Article

\title{
Application of Open Source Electronics for Measurements of Surface Water Properties in an Estuary: A Case Study of River Jadro, Croatia
}

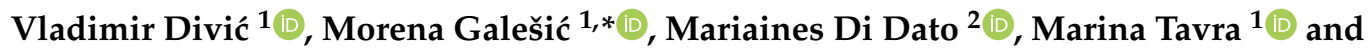 \\ Roko Andričević 1,3 \\ 1 Faculty of Civil Engineering, Architecture and Geodesy, University of Split, 21000 Split, Croatia; \\ vladimir.divic@gradst.hr (V.D.); mtavra@gradst.hr (M.T.); rokoand@gradst.hr (R.A.) \\ 2 Helmholtz Centre for Environmental Research-UFZ, Department of Computational Hydrosystems, \\ 04318 Leipzig, Germany; mariaines.di-dato@ufz.de \\ 3 Center of Excellence for Science and Technology-Integration of Mediterranean Region, University of Split, \\ 21000 Split, Croatia \\ * Correspondence: mgalesic@gradst.hr; Tel.: +385-95-564-0784
}

Received: 28 October 2019 ; Accepted: 7 January 2020 ; Published: 11 January 2020

check for updates

\begin{abstract}
There are multiple factors affecting the behavior of water properties in an estuary, including the hydraulic properties of rivers and corresponding receiving water bodies, along with the potential solutes brought by rivers. Although there are various numerical models and analytical approaches to solving particular or holistic problems in estuaries, measurements are inevitably required. In this study, we developed an innovative low-cost probe based on the Arduino platform as an alternative to more expensive measuring systems. Our device is designed to measure position, temperature, and electrical conductivity in multiple realizations, and it consists of a floating container equipped with the following components: an Arduino Mega development board, a power management module, an SD card logging module, a Bluetooth module, a temperature measuring module, a global positioning satellite (GPS) position module, and a newly developed module for measuring electrical conductivity (EC). We emphasize that all used tools are open-source and greatly supported by the worldwide community. We tested our probe during a field campaign conducted at the estuary of River Jadro near Split (Croatia). Nine probes were released at the river mouth and their position, temperature, and EC were monitored and recorded during the experiment, which ended when the probes stopped, due to the river plume attenuation. The same experiment was repeated three times. All of the probes recorded consistent temperature data, while the EC data show more variable behavior, due to the higher sensitivity of the corresponding sensor. This was expected as a part of the natural process in the estuary. The measured data were additionally used to parameterize an analytical model for mean flow velocity and salinity as a proxy concentration. This showed a good match between the experimental results and the theoretical framework. This work, although focused on water surface applications in the near field zone of an estuary, should be considered as a promising step toward the development of innovative and affordable measurement devices.
\end{abstract}

Keywords: estuaries; field measurements; Arduino; low-cost measurement system; salinity importance; conservative solute proxy

\section{Introduction}

Estuaries are dynamic ecosystems that experience constant environmental changes due to their nature of being a transition zone among land, river, and sea. Historically, estuarine science has even been considered as a "poor relation" between freshwater and marine science [1]. However, among all 
the surface water resources, estuaries and coastal ecosystem represent one of the richest and the most threatened natural systems globally [2,3]. The importance of estuaries is reflected in the value they deliver through their ecosystems, ranging from direct consumable benefits to indirect benefits that support the local biome and geophysical processes [4-7].

In an attempt to protect and preserve estuarine values, environmental directives and guidelines have incorporated estuaries within multiple regulations. For instance, in the United States, estuaries are covered by the National Estuary Program within the Clean Water Act [8], while, in the European Union (EU), they are well represented in the Water Framework Directive (WFD), the European Bathing Water Directive (EUBWD), and the Marine Strategy Framework Directive (MSFD) [9-11], and are specifically treated as transitional waters.

However, most of these programs have the same obstacle when it comes to implementation, and that is the scarcity of data, in particular, spatial data, which has already been covered by multiple studies [12-15]. The INSPIRE (Infrastructure for Spatial Information in Europe) Directive [16] addresses this issue by acting as an umbrella platform covering the spatial data infrastructure for EU environmental policies and activities. In particular, Marine Spatial Data Infrastructure (MSDI) is focused on coastal areas [17] where it is closely related to both WFD and MSFD. Similar to other Member States, Croatia has introduced MSDI into the national legislative framework within the fully functional National Spatial Data Infrastructure (NSDI). Furthermore, a planning support concept was applied [18] and key stakeholders have identified priority data themes, but there are few data available online at this moment [19]. Consequently, MSDI development should follow monitoring efforts to enable better availability of spatial data and inter-operability.

The monitoring requirements issued by the above-mentioned regulations are pressing Member States and corresponding environmental agencies to assign a significant amount of resources to obtain data on water properties. The goal is to continuously assess the ecological status of certain water bodies and work on an improvement if needed [20]. When analyzing the concentration distributions and dilution processes, which are intrinsically random, corresponding field experiments of repetitious realizations for dye release are quite expensive and tedious. In particular, Riddle and Lewis [21] studied the mixing process in coastal waters by collecting and analyzing tracer dye experiments in 37 locations (among them, 25 were from the UK, five were from beaches in Malaysia and Singapore, and the last two were from France and China). Their datasets were composed of a total of 285 dye experiments recorded between 1968 and 1996. In addition, Rodriguez et al. [22] carried out a field experiment at the Delta Ebro surf zone, in Spain, over 13-17 December 1993. Their experimental design comprised simultaneous quantification of several parameters, such as incident waves, spatial velocity, and dispersion of five types of dyes. The process was repeated for eight cases. Later, Clarke et al. [23] quantified the dispersion coefficients in Santa Monica Bay by analyzing the statistics of 14 dye releases from 1999 to 2000. Continuous research has also been done to predict some of the parameters without interfering in the environment itself, for instance in micro-tidal, river dominated estuaries in Croatia $[24,25]$ with the focus on the distribution of potential conservative pollution brought to coastal waters by rivers, or in a broader sense in New Zealand estuaries [26].

Among different water properties in estuaries, salinity is one of the most studied [27,28], both for its importance to the ecosystem (hydrodynamics and biome), and for its cost-effective measurement as opposed to, for instance, biological parameters. For instance, Wiseman et al. [29] analyzed the salinity trend of two historical datasets from estuarine waters in south Louisiana (USA); their study shows significant trends in mean salinity, salinity variance, and maximum salinity. Later, Bradley et al. [30] modeled the salinity decrease caused by a discharge reduction at Cooper River (South Carolina, USA), which occurred in 1985, thereby observing considerable changes in estuarine plant distribution. In a recent paper, Lorenz [31] reviewed the data on vertebrate fauna at Florida Bay (USA), finding a strong correlation between decrease in estuarine population and increase in salinity level. Similar relationships between salinity concentration and estuarine ecosystems indicators were observed by Spalding and Hester [32] for coastal Louisiana (USA); by Rivera-Monroy et al. [33] at Ciénaga 
Grande de Santa Marta-Pajarales Lagoon Complex (Colombia); and by Little et al. [34] in Southern England (UK). Moreover, salinity may be used to determine multiple hydrological properties indirectly (e.g., coefficient of diffusion, velocity, and concentration statistics), as shown by several authors, such as Vallino and C.S. Hopkinson [35] for Plum Island Sound estuary (Massachusetts, USA); Ho et al. [36] for the estuary of Hudson River in New York (USA); Gay and O'Donnell [37] for the Mid-Atlantic (USA); Xu et al. [38] for Chesapeake Bay (USA); Ref. [39] in the coastal zone of north-eastern Japan; and Andričević and Galešić [40] for the River Žrnovnica in Split (Croatia). This approach has been analyzed $[40,41]$, by measuring the salinity at different points in time with a commercial probe, the Sea-Bird's SBE 37-SI MicroCAT. Depending on the final goal of the comparison between measured and modeled data, different spatial configurations of the measured points were previously planned and executed accordingly within four measurement campaigns on the River Žrnovnica [42].

We emphasize that measured salinity data were well aligned with the theoretical framework based on the analytical model for solute concentration statistics. Results were good, but their quality could have been affected by the lack of temporal synchronization. That previous study was a key motivation in developing the measurement system described in this manuscript, as it would have been preferable if the points were measured simultaneously at multiple positions. Since having multiple commercial probes such as SBE 37-SI MicroCAT is rather expensive and sub-optimal, a lower-cost concept is proposed. Several previous studies have shown this kind of approach to be promising. For instance, a new multi-sensor buoy system was developed by enabling the remote monitoring of marine pressure, temperature, and atmospheric pressure [43]. Later, it was broadened to multiple other parameters, such as chlorophyll a and Chromophoric Dissolved Organic Matter fluorescence [44].

However, such field measurements are often carried by means of costly probes, which may hamper the quantity of available datasets. A possible way to reduce the cost of monitor devices is collecting data by using Arduino-based [45] sonde. Arduino is a hardware and software company devoted to designing and manufacturing open-source microcontrollers for digital devices, which are specifically conceived to be user-friendly and easy to use. In a recent study, Lockridge et al. [46] developed an innovative low-cost Arduino based sonde able to measure data in coastal applications. Their paper describes both the manufacturing phase and the application test, which was comprised of two different conditions. During the first field measurement, six sondes were used as a free floating Lagrangian drifters and the data collected were position, velocity, and salinity; whereas during the second field measurement, the sondes collected data in a fixed position underwater for a long time period. Their results show a good agreement of dataset with expected environmental conditions, thus being a reference for Arduino based sondes as a promising tool for environmental monitoring.

In this manuscript, we implemented a similar framework as the one previously addressed by Lockridge et al. [46]; however, the main distinctions are lower cost and higher flexibility due to the custom made electrical conductivity (EC) sensor, as described in Section 2.3, although our approach requires a more complex calibration procedure (Section 2.4.2). Furthermore, while the system developed by Lockridge et al. [46] was introduced to have long-term applications and specific depths (defined by mooring positions), we were exclusively interested in surface water properties data in short-term applications.

Our focus was to have multiple realizations in shorter time periods in order to obtain velocities, temperature, and salinity concentration statistics in the near field zone of an estuary. Our probes were not supposed to be left without supervision, and the main focus was to enable better validation of previously proposed analytical models by obtaining necessary parameters and testing the salinity as a proxy concentration. To obtain our goal, the probes were designed to float, to be easily deployable, light, and user-friendly. Furthermore, even though the Arduino system was used as the electronic base for the probe, the process itself is organized quite differently than other commercial options, in order to make it more cost-available, possibly even expendable, which is further explained in Section 2.3. It is important to emphasize that one may build such a probe with basic electronic tools. The cost of commercial probes is mainly due to sensors for electrical conductivity, which are often quite expensive 
and operate as black-box solutions with limited user access to the internal setup. The great advantage of developing our hand-crafted EC system dwells on its cost, i.e., less than 1/10 of an off-the-shelf version, which allows technicians to manufacture probes in large quantities. However, a downside of the proposed system is a more complex calibration scheme, as explained in Section 2.4.2.

The capabilities and potentialities of the probes were tested in a field experiment conducted at River Jadro, near the city of Split, Croatia. In Section 2 we present the study area along with a short description of field experiments. More importantly, the procedure of measurement system development (Section 2.3) and data acquisition (Sections 2.4.1-2.4.3) are described. Specific focus is given to the calculation of both velocity and salinity data, which are needed for the additional and improved validation of previous research [24,40-42]. Within Section 3.1, the obtained data are shown, while final applications for obtaining the parameters needed for further modeling are displayed in Section 3.2. In Section 3.3, we test and discuss the observed properties of the proposed measurement system, its limitations, and detected problems. Finally, we developed our conclusions on usability, achieved water properties data acquisition, and potential future applications and works (Section 4).

\section{Materials and Methods}

In this section, we present the key components of the proposed measurement framework and the area of interest. Our previous studies [24,40,42] were focused on the River Žrnovnica, whereas here we focus on a rather more significant river in the area of Split, namely the River Jadro and its estuary (Figure 1). A concept for the field experiment is introduced in Section 2.2 and followed by the detailed explanation of designing the probe in Section 2.3. The processing of raw data after the measurement campaign was performed and is explained in Section 2.4.

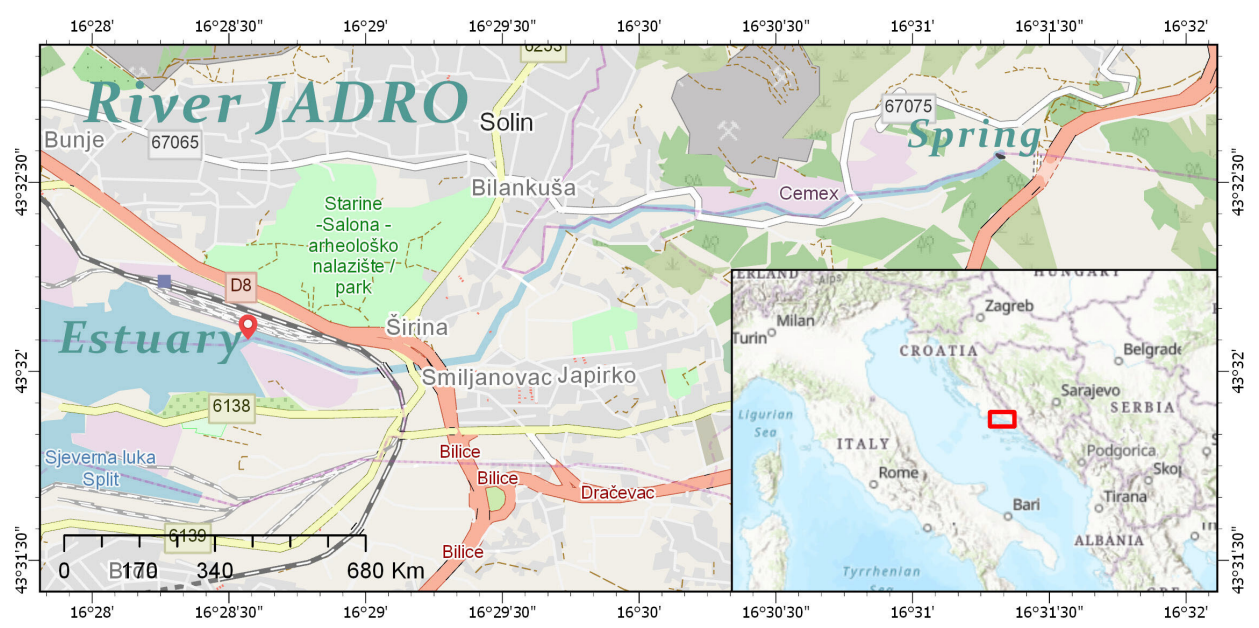

Figure 1. Case study location.

\subsection{Study Area}

Croatian rivers in the Adriatic basin have more or less stratified estuaries [24,47-49], Jadro included. Both the River Žrnovnica and the River Jadro are drawing water from aquifers in the hinterlands of the city of Split. River Jadro springs at $33 \mathrm{~m}$ a.s.1. at the intercepting bases of local hill Kozjak and mountain Mosor, which are mostly built from limestone and flysch deposits [48]. The total length is $4.2 \mathrm{~km}$, from spring to mouth, located in the far eastern part of Kaštela Bay (Figure 1). The river goes through the urban area of Solin, a small town near Split, where it branches in several directions, eventually connecting into the same channel before the mouth itself.

There are also five flash flood streams that are mostly dry except during rainy periods. The influence of sea water has been recorded and modeled reaching up to $1 \mathrm{~km}$ upstream [48], and there have been complaints by local fishermen about the lack of fish due to the increased salinity. Potable water for the whole city of Split and most of the local region is captured at the spring of Jadro. 
In addition to flash flood streams, Jadro has a few smaller tributaries, but again, they are dry most of the year. Research conducted here does not include flash flood flows since the measurement campaigns have been conducted in the summer during a rather dry period, namely on 3, 12, and 13 July 2018. Our campaign focused on the part of estuary that is river-dominated, being characterized by expected mesohaline properties [50] with salinity values up to 20 PSU (practical salinity unit).

\subsection{Field Measurements}

Three different measurement campaigns were organized during the month of July 2018 in order to test the developed prototypes and the implications for the various applications. The initial focus was to further validate the analytical model for concentration statistics in estuaries developed by Galešić et al. [24] and later expanded to a spatially integrated model by Andričević and Galešić [40]. However, these particular validation procedures will be further analyzed in future work. In this manuscript, we focus on giving an alternative and low-cost way of measuring surface salinity by representing the data, analysis, application potentials, and conclusions for the first measurement campaign conducted on 3 July 2018.

The aforementioned measurements were conducted during the morning, from 09:00 to 12:00, when there were minimal chances for disturbances caused by wind, waves, and boat generated waves. The river flow was $2.7 \mathrm{~m}^{3} / \mathrm{s}$, the wind speed for the corresponding 3-h period was between 0 and $2.1 \mathrm{~m} / \mathrm{s}$ (mostly from the southeast, which makes the study area quite protected due to the terrain properties), and the water level change was around $2 \mathrm{~cm}$. Described conditions are presented in Figure 2 and obtained from the local Institute of Oceanography and Fisheries [51].
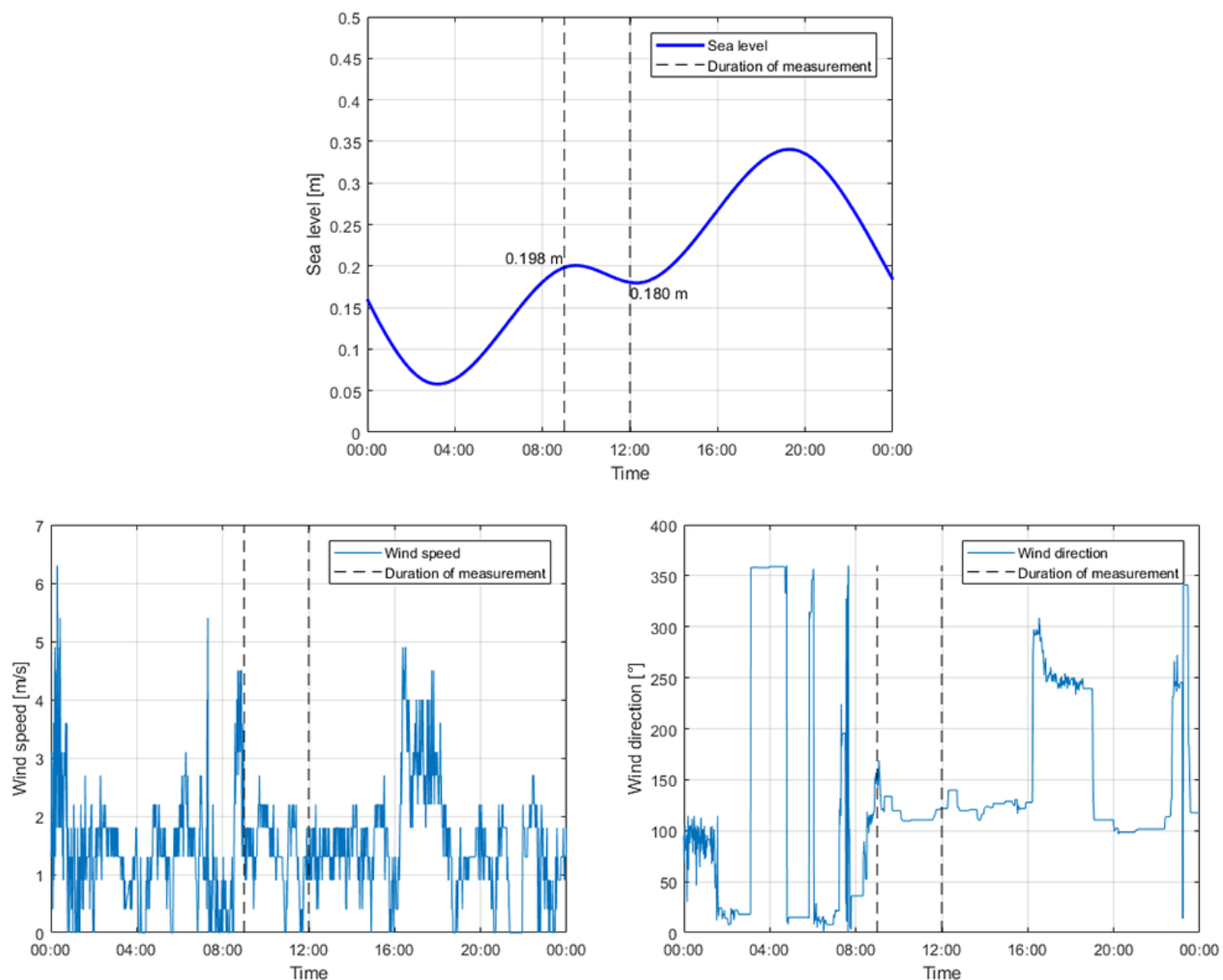

Figure 2. Field measurements conditions: sea level (top); wind speed (bottom left); and direction (bottom right).

Furthermore, several velocity measurements were conducted at the defined source point (the starting position for probe releases, red paddle point in Figure 1) with a hydrometric wing (SEBA-Mini 
Current Meter M1 with start velocity of $0.025 \mathrm{~m} / \mathrm{s}$ ). The depth-averaged velocity was $0.29 \mathrm{~m} / \mathrm{s}$. The velocity was measured at $0,0.2,0.3$, and $0.5 \mathrm{~m}$ from the surface, as the $0.5 \mathrm{~m}$ was the average depth of the river's buoyant plume at the source point. From the $1 \mathrm{~m}$ depth to the bottom $(-2.1 \mathrm{~m}$ a.s.1. at the time of measurement) was a motionless stabilized salt wedge (see Section 3.1). Probes were equipped with a wireless Bluetooth link (see Section 2.3), which enabled setup and monitoring without exposing the electronics to humidity. During the measurement campaign, the status of probes was monitored using an Android tablet with a custom built GUI (graphical user interface) for probes. The GUI was built using the BlueTooth Electronics software by Keuwlsoft [52].

This campaign was focused on releasing the probes from more or less the same position, defining a source or initial starting point for real life surface Lagrangian transport; hence, the chosen point was just below an old, out of use, railway bridge (red paddle point in Figure 1). The Arduino based probes, which are explained in more detail in Section 2.3, were released from the moored boat just below the bridge, approximately at the centerline of the river mouth. During the probes preparation phase in laboratory, but after the setup and calibration, buoyant plastic containers were painted bright pink in order to be more visible in the field, as shown in Figure 3. Once the probes were released, we would follow them quite slowly, in a boat without turning the motor on, to minimize the disturbance of natural flow conditions. The probes would go as far as the river plume has dominance in the surface upper layer, so that when that has been exceeded and sea becomes more influential, the probes would then stop and idle at the same place (as presented further in Section 3). After we were sure that the probes are not moving significantly any further downstream, we would collect them and return to the initial point to release them again. This procedure was repeated three times, and the obtained observations are described in Section 3.

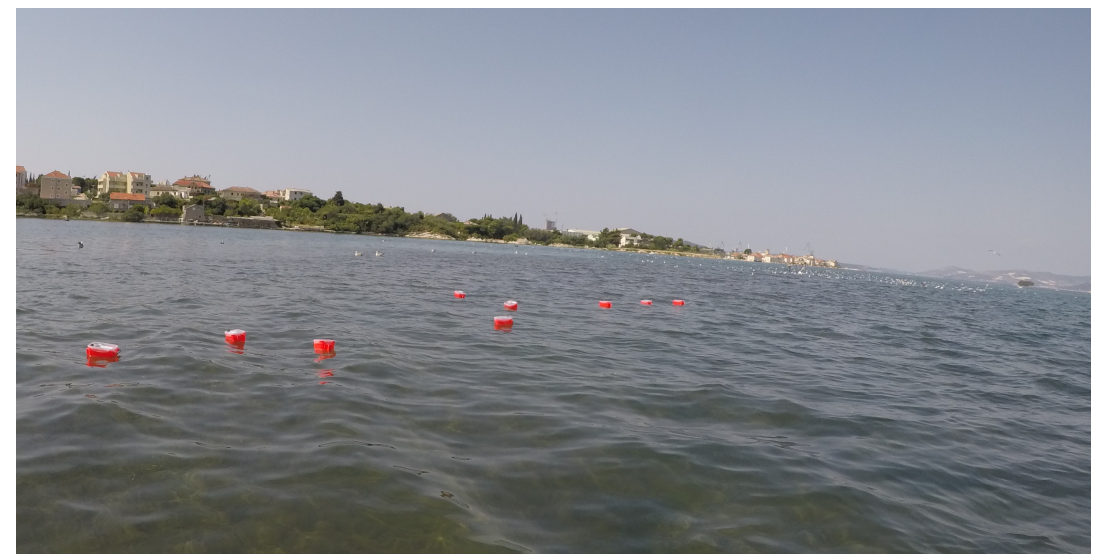

Figure 3. Second release of the probes (photo taken from the boat).

\subsection{The Arduino Based Measurement Probe}

The main idea behind developing this measurement system is affordability, flexibility, and the ability to have a simple design system for obtaining spatially referenced surface data of temperature, electrical conductivity, and velocity. All the tools used are open source and greatly supported by the worldwide community. The materials used for the single measurement probe at the time of building amounted to approximately $105 \mathrm{EUR}$, and required up to 20 engineering hours, therefore presenting a low-cost alternative to commercially available options. If additional costs generated by more complex calibration procedures are taken into account, the aforementioned unit price may increase up to an estimated value of 130 EUR when a batch of ten is produced. These costs might include at least one of the lower cost calibrated EC probes (e.g., the Conductivity K $1.0 \mathrm{Kit}$ [53]), the costs of saline solutions, and an additional two engineering hours per probe.

The system is based on the Atmega microprocessor family supported by the open hardware Arduino platform [45]. Arduino development boards support microprocessors with all the necessary passive and active electronic components, while the Arduino integrated development environment 
(IDE) provides easy coding for microprocessor operations in a common programming language, C. In addition to Arduino development boards, multiple modules were used to perform specific activities of the measurement platform. The main organization scheme is given in Figure 4. To provide reliable connections between components and simplify the field repairs, the motherboard was designed with simple header connections that require no soldering.

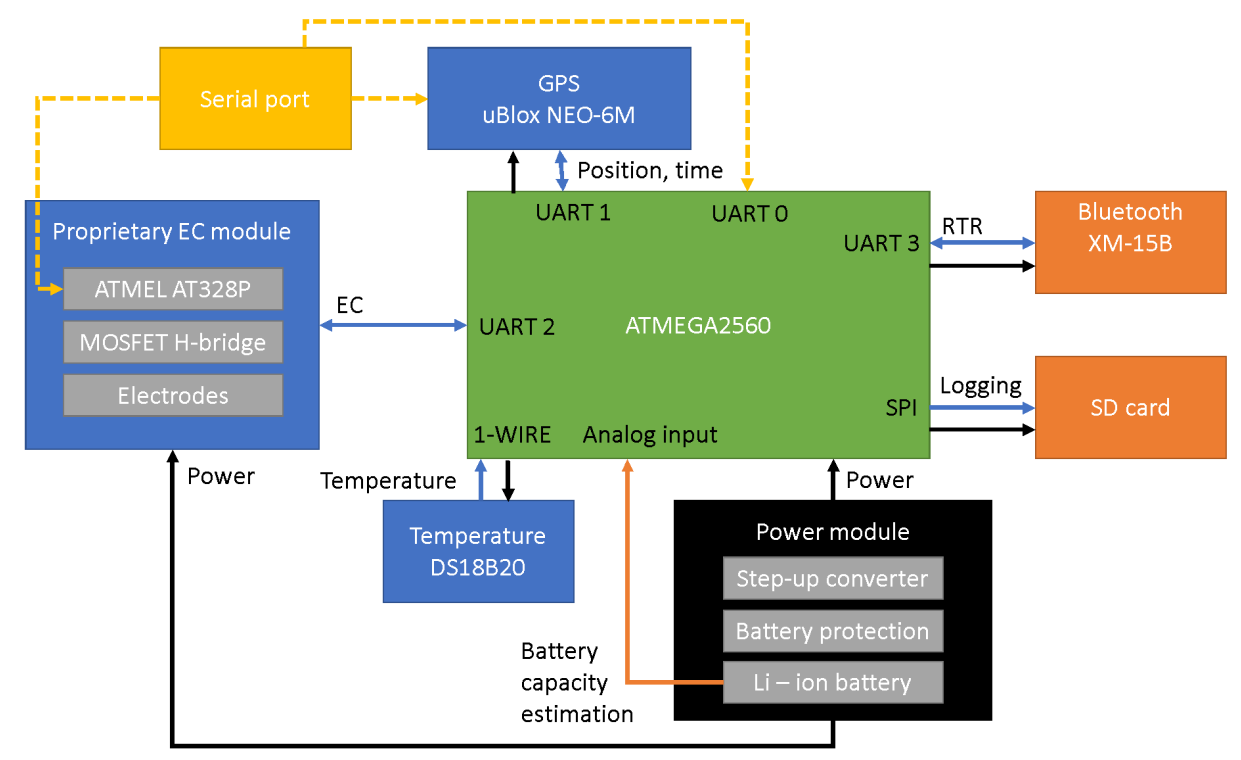

Figure 4. The schematic representation of the Arduino based probe system.

The system can be broken down to these main components: Arduino Mega development board, power management module, SD card logging module, Bluetooth module, temperature measurement module, global positioning satellite (GPS) position module, and the newly developed electrical conductivity (EC) module. The Arduino MEGA development board is based on the ATMEGA2560 microprocessor [54]. ATMEGA2560 is more robust than ATMEGA328P or ATMEGA32U4, which have been used in other variants of Arduino development boards. The main reasons for using ATMEGA2560 over other options are the larger program memory size ( $256 \mathrm{kB}$ vs. $32 \mathrm{kB})$ and four hardware serial ports that were necessary for communication with other modules. The ATMEGA2560 is more expensive than other variants (at the time of writing, unit price was approximately $75 \%$ more expensive) but still within the range of affordable solutions.

The power management module was custom made for this application. It consists of a lithium-ion battery (type 18650, capacity of $2000 \mathrm{mAh}$ ), battery protection circuits, and a voltage step-up converter. Used batteries have standardized physical dimensions and satisfactory energy density. The system was drawing an average of $250 \mathrm{mAh}$ in use, which enabled a single charge to be active for $8 \mathrm{~h}$. In the case of a fault (e.g., a short circuit due to water intrusion, overuse, or extreme external heating), the battery protection circuit disconnects the battery to prevent damage. The battery operates at a nominal voltage of $3.7 \mathrm{~V}$; hence, a voltage step-up converter is used to increase the voltage to $5 \mathrm{~V}$, as required by all modules in the system. The battery capacity is estimated according to the battery voltage, which is measured before the step-up circuit, using an integrated analog digital converter (ADC) in the ATMEGA2560. To have a fixed voltage reference, an internal $1.1 \mathrm{~V}$ voltage reference is used. The battery voltage is scaled using a voltage divider with optimal resistance to minimize battery drain without interfering with the impedance of ADC. An SD card module is used to record data on SD cards for post-measurement data analysis. A Bluetooth module is used for real-time data monitoring using a PC or mobile phone serial terminal software. This connectivity was used only to spot check the operating drifters without opening the buoy and to download data on demand. 
The GPS module is used as both a location device and time keeping device. Specifically, the uBlox NEO-6M module is used to communicate over a serial port using the standard NMEA0183 protocol [55]. Instead of a standard real-time clock, we used GPS modules for time keeping as they ensure time synchronization between probe units and reduce temporal drift. The NMEA0183 sentence parsing is done via an Arduino TinyGPS library. Temperature and electrical conductivity data are collected using a DS18B20 digital temperature sensor [56] and custom made EC module. All of the components, except for the sensing part of temperature and EC module, are contained within a plastic container (see Figure 5) where the overall volume and mass of the drifter sensor package is made to be half submerged. To prevent the overturning of drifters, the components and additional weights are distributed within the container in order to have the center of mass near the center of the bottom plane.
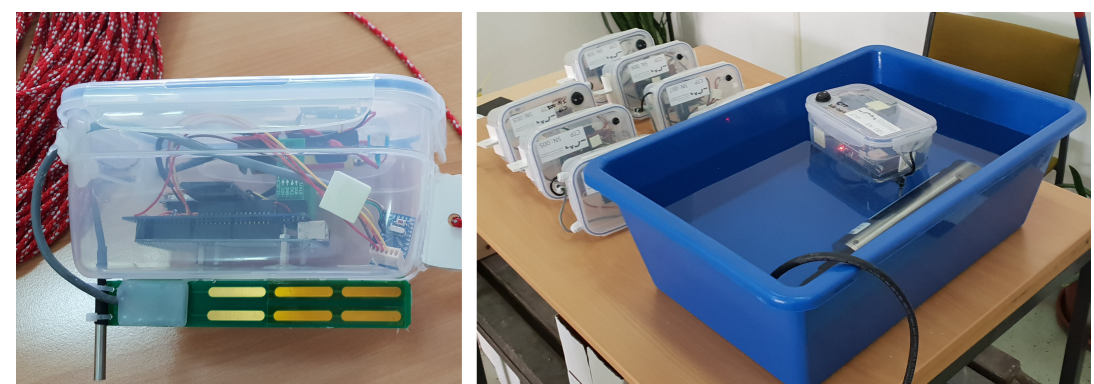

Figure 5. An example of a probe with exposed electrodes below the plastic container (left); and the calibration procedure in laboratory with the industrial probe (right).

The DS18B20 is in a standard TO-92 package but sealed in a thin, stainless steel cylinder enclosure for protection against salt water intrusion. Such sensors have a typical accuracy of $\pm 0.5{ }^{\circ} \mathrm{C}$ in measurement range from -10 to $85^{\circ} \mathrm{C}$. For our intended applications, where the temperature range is restricted in the range of $15-30{ }^{\circ} \mathrm{C}$, characteristic accuracy was $0.1-0.2^{\circ} \mathrm{C}$.

The electrical conductivity measurement module is constructed from the Arduino Pro Micro development board, and a monolithic H-bridge for driving alternative currents and passive components as low pass filters. The exposed surfaces of gold-plated printed circuit boards (PCBs), i.e., electrodes, were used as active sensors (Figure 6). The module has three pairs of electrodes to enhance sensitivity for measurements in a low conductivity medium. In brackish water, only one pair was needed. The other two pairs were insulated using a double coat of clear acrylic lacquer (PLASTIK 70). The single sensing pair has a surface of $15 \mathrm{~mm}^{2}$ and are set $10 \mathrm{~mm}$ apart.

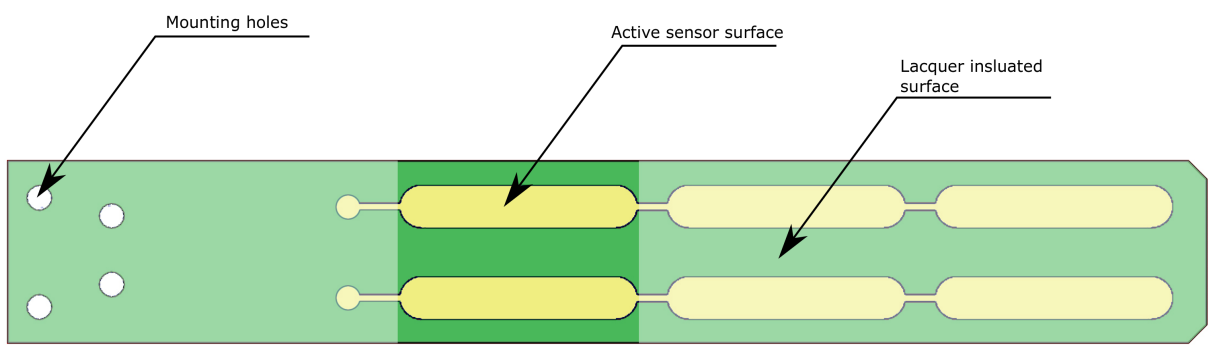

Figure 6. The printed circuit board (PCB) for the electrical conductivity sensor.

The operating principle of the module is as follows: by using the H-bridge $\left(\mathrm{Q}_{1}\right.$ to $\mathrm{Q}_{4}$ in Figure 7$)$, the alternating voltage is applied on the series connector between the known value resistor and the active sensors inserted into the medium. This connection between known resistance $\left(\mathrm{R}_{1}\right.$ in Figure 7$)$ and resistance across sensing surfaces $\left(R_{x}\right.$ in Figure 7$)$ forms a voltage divider that enables the correlation of voltage measured between resistors and the resistance of the unknown medium. The output of the voltage divider ( $\mathrm{V}_{\text {out }}$ in Figure 7 ) is routed to the ADC of the Arduino Pro Mini. The measurement is 
carried out only in the positive phase of the cycle, while the negative voltage phase is used to prevent electrolysis near the sensor surface, which would contaminate the measurement surface.
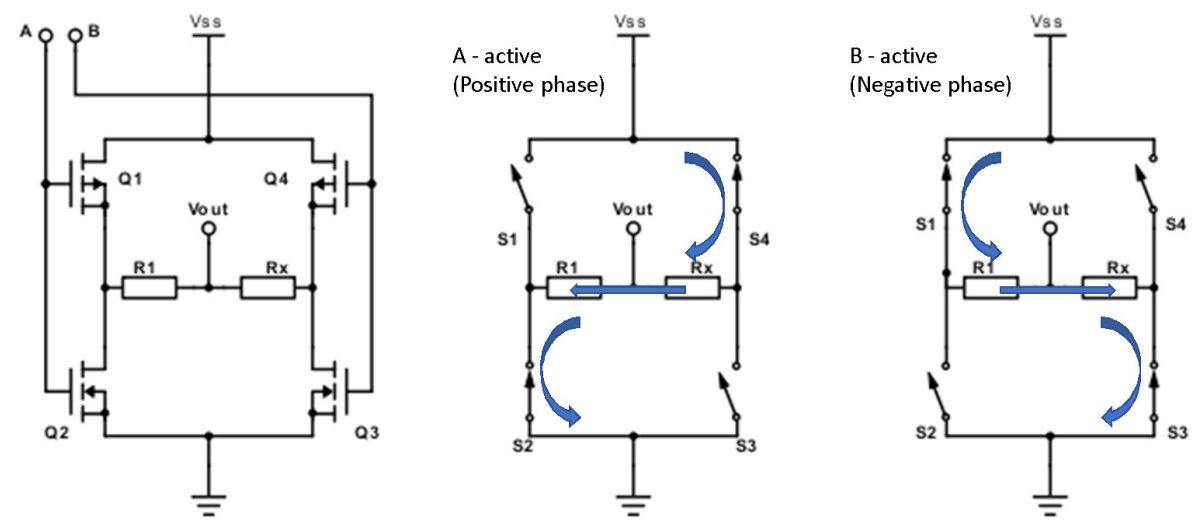

Figure 7. The $\mathrm{H}$ bridge for the EC sensor schematic (left); the blue arrow denotes current flow in positive phase (bridge MOSFETs approximated with switches) (middle); and the blue arrow denotes current flow in negative phase (right).

Although a simplified analytical model may be obtained and used as an approximation for the electrical conductivity, a calibration with a commercial EC probe (Sea-Bird SBE37) was performed in the laboratory. The process of probe calibration, along with other crucial data processing is described within Section 2.4.

\subsection{Data Processing}

Finally, the described system delivers temperature data, ADC records and raw GPS information containing time, longitude, latitude, elevation, and horizontal dilution of precision (HDOP). Data are stored on the SD card with a frequency of $8 \mathrm{~Hz}$. For further application of such obtained records, additional data processing was needed, which is described below, starting from smoothing and clearing the GPS information (Section 2.4.1) up to derivation of the salinity data (Section 2.4.3).

\subsubsection{GPS Data}

Global positioning satellite (GPS) systems are widely available and used for positioning on a global scale. However, this system suffers from accuracy issues for precise measurements. Low-cost GPS receivers usually have accuracy in a $10 \mathrm{~m}$ range, which is enough for 1D tracking (tracking along known roads) and rough surface tracking. Higher-cost systems may have improved accuracy up to the $10 \mathrm{~cm}$ range, especially geodetic measurement systems and real-time kinematic (RTK) systems. Furthermore, accuracy issues are exacerbated in marine applications, due to the complex superposition of multiple reflections of GPS signals over the sea surface and variation of the atmosphere in the path of a signal. Hence, the calculation of a probe's velocity by a standard derivation of position over time is not possible under these conditions, due to the high level of positional noise.

The implemented low-cost uBlox NEO-6M GPS receiver module had the optimal balance between specifications and cost. It features a 50 channel receiver, a $5 \mathrm{~Hz}$ update frequency, and a theoretical horizontal position accuracy of $2.5 \mathrm{~m}$ [57]. The GPS receiver was connected to the probe motherboard via a UART (universal asynchronous receiver-transmitter). From standard NMEA0183 sentences sent from the GPS, the main microprocessor parsed the absolute time, latitude, longitude, HDOP, age of last fixed position, and number of observed satellites (Figure 8). Figure 8 (top) presents a more or less constant number of observed satellites along with corresponding HDOP, and these data were used when reconstructing the trajectory (Figure 8, bottom), e.g., by lowering the weights of the points with displayed spikes in HDOP. Nevertheless, the mostly low HDOP indicated the possibility of using a smoothing spline, as described below, reliably. 

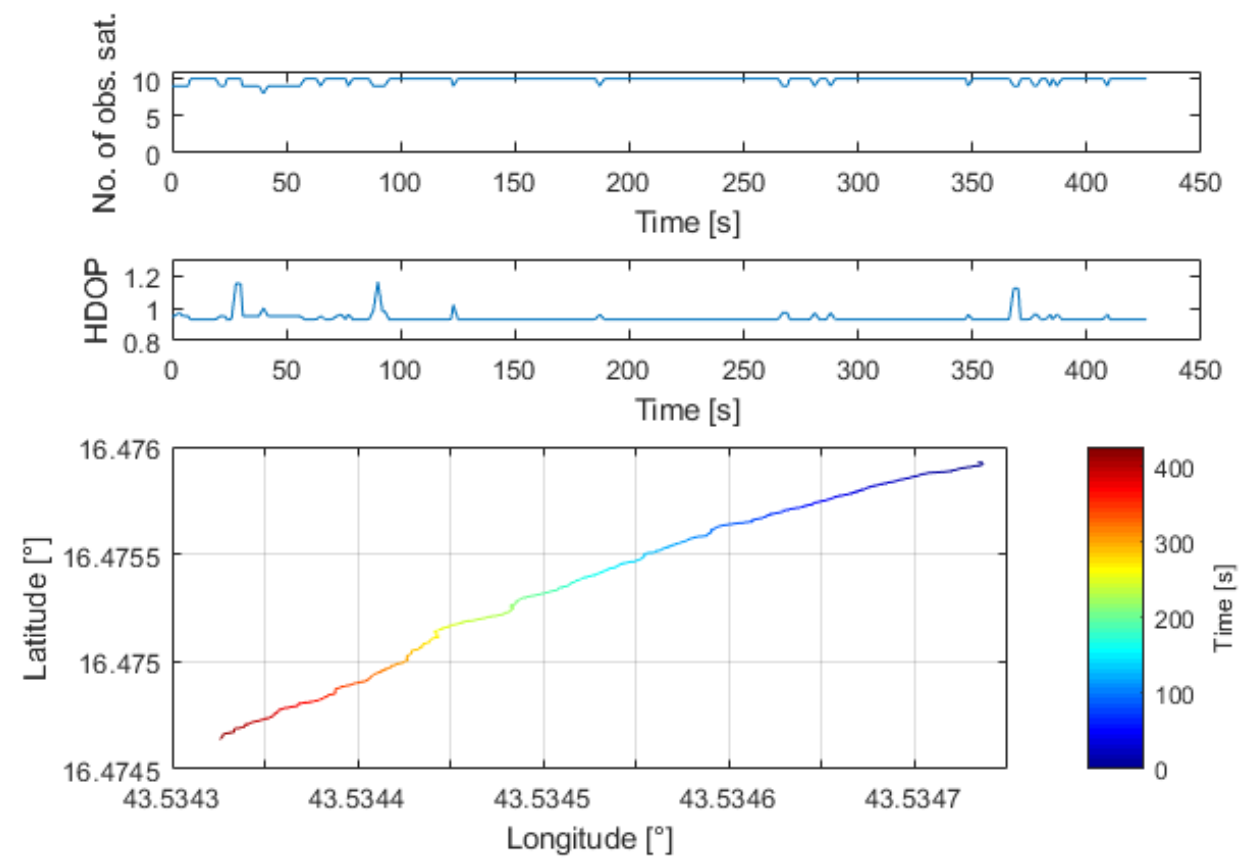

Figure 8. Raw output of the global positioning satellite (GPS) sensor: number of observed satellites (top); horizontal dilution of precision (HDOP) (middle); and trajectory of the probe in world coordinates (bottom) (time is color coded).

An additional analysis was performed on the raw data to retrieve more accurate positions and velocities of the probes. There are multiple approaches for minimizing GPS errors, such as least square spline approximation, the kernel-based smoothing method, and implementation of a discrete Kalman filter [58]. For this application, a smoothing cubic spline method was used to obtain smooth trajectories and velocities. The first step of the algorithm includes translation of the recorded world coordinates to the Universal Transverse Mercator (UTM) coordinate system, centered at a position near the release point of the probes with a rotated local coordinate $\mathrm{x}$ in the direction of the mean flow, while the $y$-axis remained positively oriented. To obtain the velocity of the probe, the newly obtained spline had to be referenced in time. By splitting the local $x$ and local $y$ components and relating them in time, two datasets are prepared for spline smoothing. The splines are then obtained by minimization of the expression:

$$
p \sum_{i} w_{i}\left(y_{i}-s\left(x_{i}\right)\right)^{2}+(1-p) \int\left(\frac{\partial^{2} s}{\partial x^{2}}\right)^{2} d x
$$

where $p$ is the parameter of smoothing, $w_{i}$ is a weight coefficient of data points, $\left(x_{i}, y_{i}\right)$ are data points, and $s$ is the smoothing spline [59]. Weight coefficients are calculated by multiplication of $1 / H D O P$ and the number of satellites. This is not the most precise solution, but is an adequate approximation for point position accuracy. The parameter $p$ has been chosen in a way to maintain features of the trajectories, the deflections from recorded position in order of sensor accuracy, and to keep the velocity profile smooth.

The output of the smoothing filter is displayed in Figure 9. For this measurement session, all probe data were filtered using the smoothing spline method, with parameter $p=10^{-6}$. Such a parameter was chosen to have the filtered data deviate less than $2.5 \mathrm{~m}$ with respect to the original data, hence obtaining the theoretical sensor accuracy from the sensor datasheet [57]. Speed profiles of the probes have a steady decline, as is observable in the original data trend (Figure 9, bottom) and previously published work [24]. 

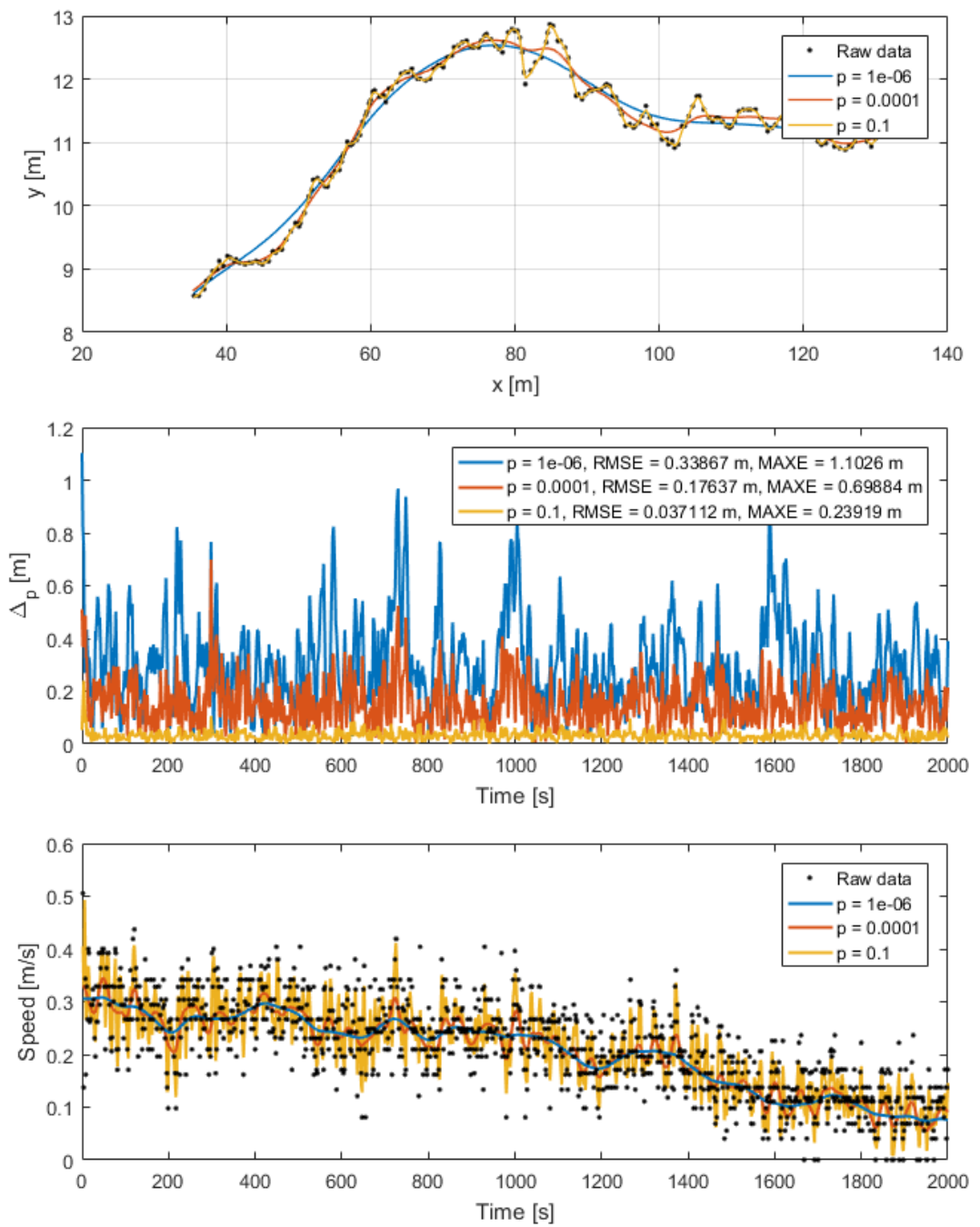

Figure 9. Smoothing spline for different parameters $p$ : smoothed trajectory with highest deviation vs. input data (top); deviations in the position of the point depending on parameter $p$ (with the root mean square error (RMSE) and the absolute error displayed in the legend) (middle); and the derived speed from the raw data vs. the derived speed from the filtered data (bottom).

\subsubsection{Electrical Conductivity Data}

As mentioned in Section 2.3, the module for electrical conductivity was custom made for this probe. This module is a standard electronic circuit with simple analytical model. However, the components of budget builds such as this have large tolerances. For a higher quality build, passive components should have been trimmed, and active components analyzed individually, as opposed to taking the manufacturer's datasheets. Such a process requires high-end components and specialized equipment, which is an expensive approach and not part of the proposed low-cost system. However, a calibration process was needed to remove most uncertainties from the equation by relating the digital readout to independently measured physical variables.

As the numerical difference between PSU (practical salinity unit) and physical salinity (kg salt per $\mathrm{kg}$ water in parts per thousand) is very small [60], the testing and calibration of the probes were conducted in the laboratory with scaled values of sodium chloride (\%) in a large plastic container, and the previously calibrated Sea-Bird SBE37 probe (which records temperature, electrical conductivity, and salinity in PSU), as shown in Figure 5 (right). The tank was initially filled with distilled water and then the calibration was performed in steps. In each step, a precisely known mass of sodium chloride was added to the tank and stirred thoroughly until all salt was dissolved in the water. Sea-Bird 
SBE37 was used to monitor the dissolving process simultaneously. The conductivity sensing part of the probe was at the same depth as Sea-Bird's sensor, to reduce the effects of salt distribution over depth. Finally, each probe was set in the water, connected to a tablet via Bluetooth, and multiple conductivity digital output and temperature readings were recorded for further analysis. The range of salinity was 0-34 ppt, divided into 10 steps. The monitored temperature was steady and accurate during the process (the same value was recorded by the proposed probe's temperature sensor and Sea-Bird's sensor).

A calibration analysis was done after acquiring data for all 10 steps described above. The systematic errors were removed (such as trapped air on the surface of the sensor, communication errors, etc.), then the averaged reading for every salinity level and for every probe was obtained, and finally an appropriate curve was fitted to the measured data points. The equation finally used for fitting the measured data was:

$$
E C[S / m]=a \cdot X^{b}
$$

where $E C$ is the real electrical conductivity in $S / m$ while $X$ is the averaged and cleaned digital readout from the Arduino ADC ( 0 is equal to $0 \mathrm{~V}$, and 1023 is equal to $5 \mathrm{~V}$ ). Parameters $a$ and $b$ were obtained from a function fitting procedure using the nonlinear least square method. Finally, fitting curves were obtained along with measures of goodness of fit. The typical four metrics are displayed in Figure 10. The adjusted $\mathrm{R}^{2}$ metric describes how the function was chosen, taking into account degrees of freedom (number of data) for fit. Values, for all probes, are above 0.85 , which indicates that appropriate functions were chosen. Next, two metrics, root mean square error (RMSE) and mean absolute error (MAE), describe typical errors from measurement. The difference of these two metrics are that larger deviations have a stronger effect on RMSE, while MAE linearly combines all errors. Furthermore, absolute errors have been normalized by corresponding measured values and averaged over all measurements per probe. Such a metric, namely averaged relative error (Figure 10, right), gives an equal importance over the whole measuring range.

Finally, the MAE for all probes was less than $0.1 \mathrm{~S} / \mathrm{m}$ while RMSE was less than $0.5 \mathrm{~S} / \mathrm{m}$. In Figure 11, a distribution of absolute error averaged over probes for different values of salinity is shown. One may notice that most of the errors are in the area with higher salinity, as expected from the architecture of the measurement system. By reducing the range of measurement to 25 PSU, we can obtain much smaller error metrics. This reduction in range did not limit our usability of probes, since the target area of the estuary exhibits significantly lower salinity than the open sea (in the Adriatic Sea, salinity is around 38 PSU), 20 PSU at the mesohaline estuary.
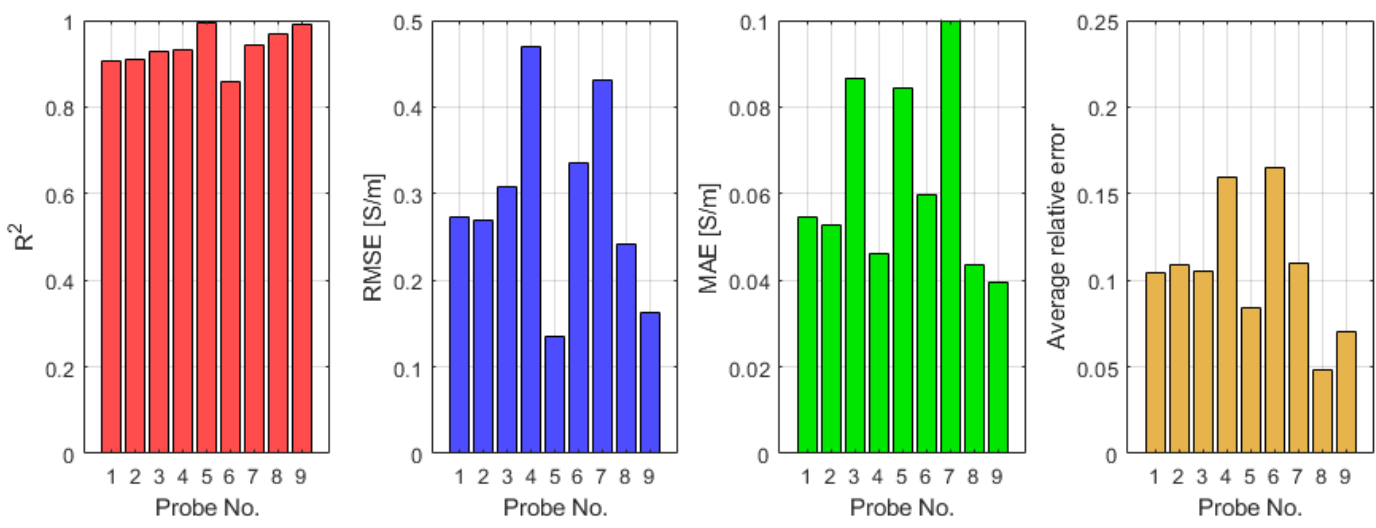

Figure 10. The metrics of calibration. 


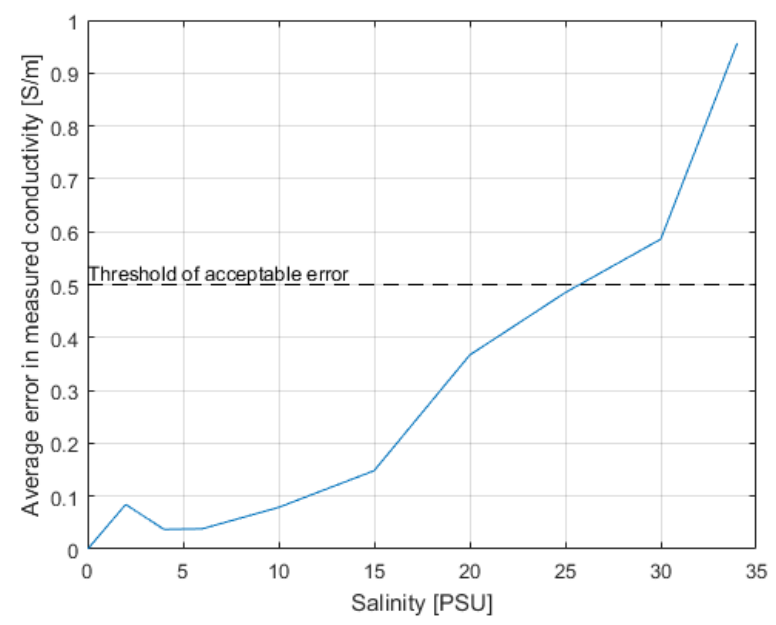

Figure 11. The distribution of mean absolute error for all probes for different salinity levels.

\subsubsection{Salinity Data}

Following the process, which is usually implemented in off-the shelf solutions, we have introduced the sensors for temperature and electrical conductivity (EC). EC was obtained from the ADC output, as explained in Section 2.3. Once the temperature and electrical conductivity were obtained, the salinity was calculated using the practical salinity scale (PSS) derived in 1978 by Perkin and Lewis:

$$
S=\sum_{j=0}^{5} a_{j} R_{T}^{1 / 2}+\frac{(T-15)}{1+k(T-15)} \sum_{j=0}^{5} b_{j} R_{T}^{1 / 2} .
$$

In Equation (3), $R_{t}=R /\left(R_{P} r_{T}\right)$ where $R=E C(S, T, P) / E C(35,15,0)$ is the electrical conductivity ratio between the measured value and the baseline for the standard potassium chloride $(\mathrm{KCl})$ solution at $35 \mathrm{ppt}, 15^{\circ} \mathrm{C}$, and 0 pressure in decibars, while $R_{P}$ and $r_{T}$ are calibrated factors of measured pressure and temperature, respectively. Our data were measured at the surface due to the design purpose of probes, thus the $P$ in $R$ is zero all the time. For the salinity calculation, we used the same baseline conductivity value as the Sea-Bird SBE37, i.e., $E C(35,15,0)=42.914 \mathrm{dS} / \mathrm{m}$. The parameter $k$ has the value of 0.0162 for the ranges of salinity between 2 and $42 \mathrm{PSU}$, and temperature between $-2{ }^{\circ} \mathrm{C}$ and $35^{\circ} \mathrm{C}$, while $a_{j}$ and $b_{j}$ are fitting parameters defined by the practical salinity scale (PSS) equations from 1978. More on the PSS equations may be found in [61].

An example for the explained data is given in Figure 12 for the ninth probe in the first realization (first release of the probes). The corresponding datasets for temperature (Figure 12, top left), electrical conductivity (Figure 12, top right), and salinity derived by Equation (3) are shown for the length of the probe's trajectory (a little less than $400 \mathrm{~m}$ from the source). Salinity clearly depends on both temperature and conductivity; however, conductivity has a dominating effect, as depicted by the shape of the curve itself (Figure 12). 

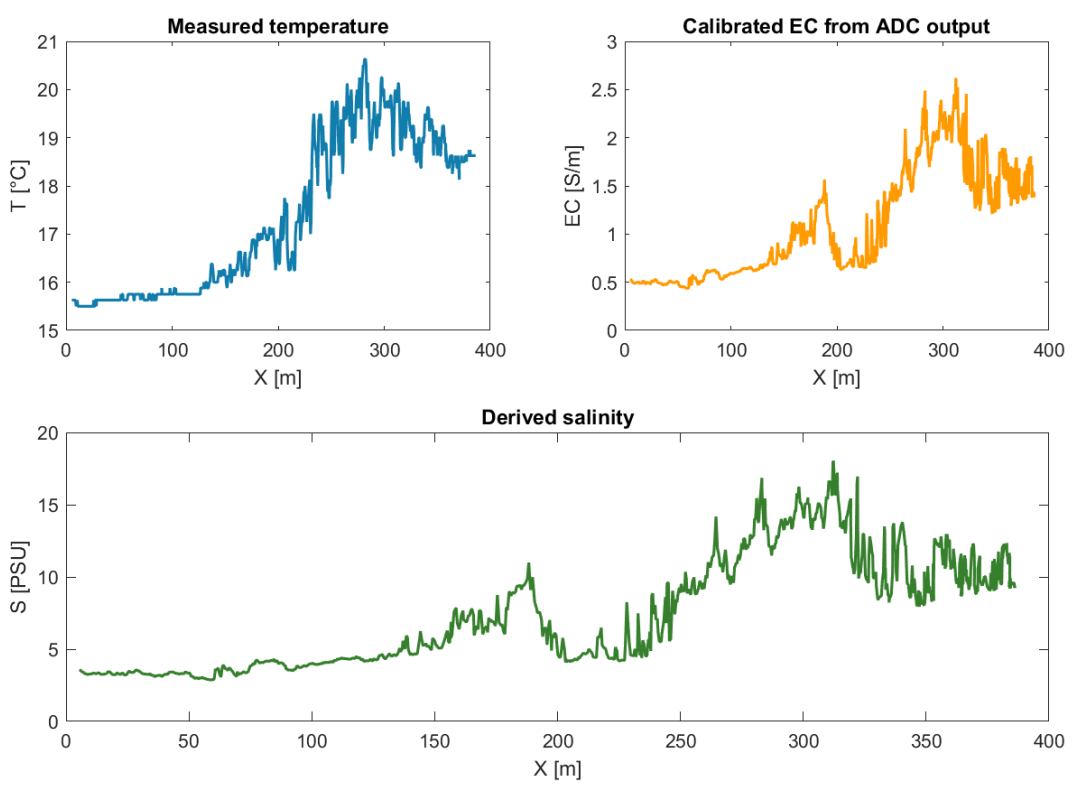

Figure 12. Derived salinity for Probe 9, Realization 1.

\section{Results}

In this section, we discuss the main results of the conducted measurements and data analysis. Since the main goal was to test the efficiency of the developed probe system in obtaining adequate positioning, velocities, temperature, and salinity at multiple points simultaneously, we present here the final data (Section 3.1). However, to further validate a previous hypothesis on mean velocity profiles [24] and the potential of salinity as a proxy concentration [40-42], additional analysis and comparisons with analytical solutions are presented in Section 3.2. In Section 3.3, we discuss the pros and cons of the proposed measurement system and its capabilities.

\subsection{Measured Data}

Nine probes were released from the river mouth point, indicated as "source" in Figure 13, and they were then collected after almost completely stopping, usually before reaching $500 \mathrm{~m}$ from the source, as previously mentioned in Section 2.2. The planar view of the measured trajectories for all three realizations is given in Figure 13, where the chosen study area is given with according bathymetry data (contour lines indicating each meter of depth change). Vertical profiles of salinity were measured with Sea-Bird's SBE 37-SI MicroCAT at minimally 10 different depths for four different positions, as shown in Figure 13, and the results are given in Figure 14.

The results from the vertical profiles clearly show the salt wedge stratification, which typically occurs in similar estuaries in Croatia [24,47,49], and was previously detected in the River Jadro by Ljubenkov and Vranješ [48]. Such behavior causes the freshwater to be mostly contained in the upper layer that is consistently decreasing in thickness as one goes downstream, e.g., freshwater layer reaches up to a $1 \mathrm{~m}$ depth at the river mouth (vertical profile 1 in Figure 14) as opposed to only 20-30 $\mathrm{cm}$ at the farthest vertical profile (vertical profile 4 in Figure 14). 

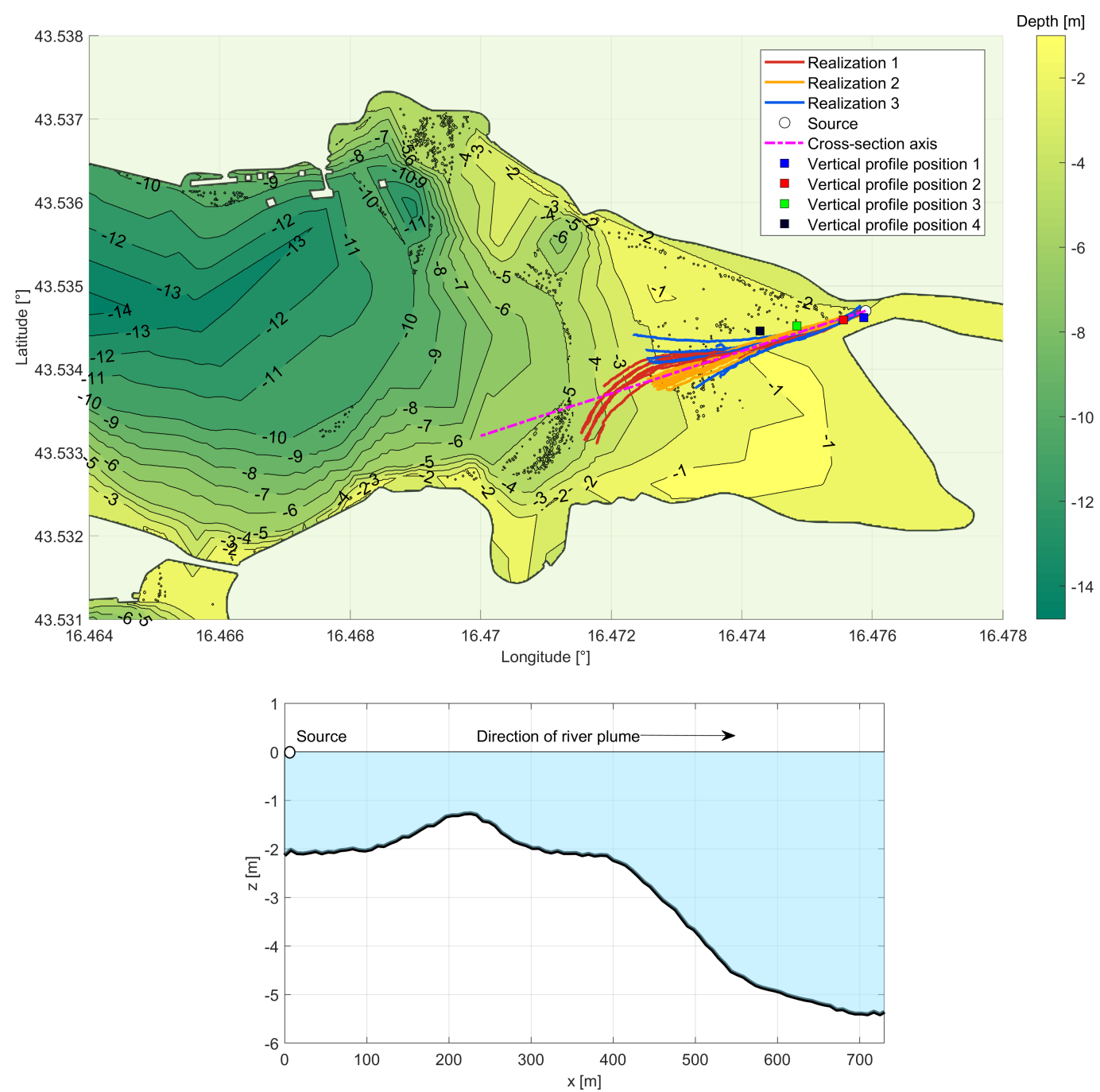

Figure 13. Planar view of the study area with annotated trajectories of probes and vertical profiles positions (top); and longitudinal cross section (bottom).

In the first realization, we let the probes idle a little more to be sure they had come to a full stop, therefore more marine influence was visible on their trajectories (red lines in Figure 13) in a slight swivel to the south part of the estuary. The interaction between the positively buoyant river plume and the receiving water body has been analyzed by several works [62,63], which provide different formulations for the river-dominance domain. This behavior may not be predicted precisely, as it is the result of a complex interplay between river and sea. Therefore, we assumed the border of influence by visual observation and consequently we collected the probes earlier in the second and third realizations since the river plume domination seemed to diminish after $300 \mathrm{~m}$ from the source point. All further data are presented for those $300 \mathrm{~m}$ accordingly. 


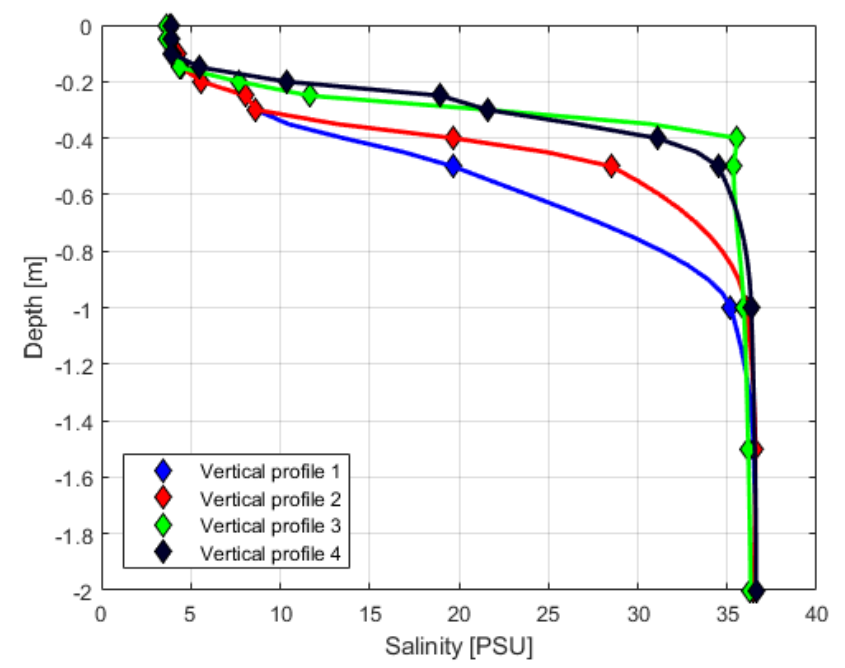

Figure 14. Vertical salinity profiles indicating the presence of the salt wedge stratification.

Velocities were calculated from the GPS data obtained and recorded on SD cards within the prototypes, as described in Section 2.4.1. Although velocity had multiple directions, all but the stream-wise were negligent (less than 10\%), therefore Figure 15 presents all the stream-wise velocity profiles for each probe (different panels) and for each of the realizations (different colors in the same panel). The quality of obtained data varies with each probe, since certain discrepancies have been noticed due to the different occlusions to GPS signal and electrical conductivity sensor (which are described in detail below). Moreover, for comparisons with the analytical velocity profile, Probes 1, 2, 5 , and 8 were later excluded due to these inconsistencies.

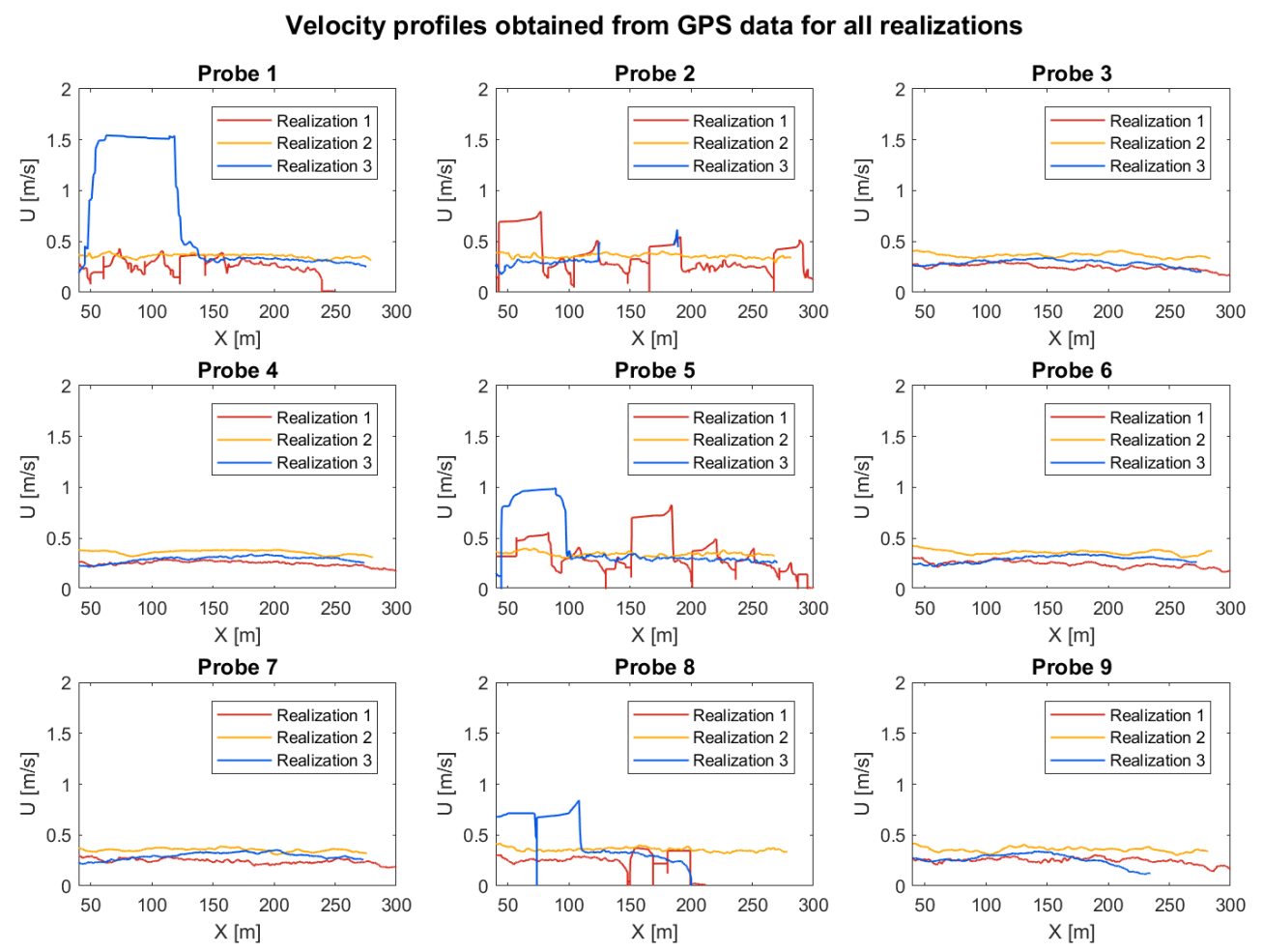

Figure 15. Velocities obtained by GPS data. 
Temperature is an important property in any water resources due to its effect on the level of dissolved oxygen [64-66] and consequently on the existing biome there. In estuaries, due to their dynamic nature, the temperature fluctuates, and additional variations occur when potential groundwater discharges, precipitation, or insolation are present. Since the temperature sensor was more or less insensitive to all the potential environmental conditions (e.g., an air bubble stuck at the electrical conductivity sensor), recorded temperature data are rather consistent with the expected physical behavior (see Figure 16). For the first $100 \mathrm{~m}$ from the source point, most of the probes recorded a consistent river surface temperature in the range of $15-16{ }^{\circ} \mathrm{C}$ (also consistent with some of the previous measurements for the River Jadro during summer [48]). Afterward, temperature slowly started to fluctuate as the sea water influence increases (at $150 \mathrm{~m}$ from source), finally reaching the ambient sea temperature of around $21-22{ }^{\circ} \mathrm{C}$, in Kaštela Bay. The $\mathrm{X}$ distance in the figure, again, represents the stream-wise direction, which does not necessarily mean the straight line from the source but rather a trajectory. However, for most probes, the first realization had the furthest distance, hence the red line in Figure 16 reaches the ambient temperature. The first realization's trajectories also reach more salty water due to the inclination of the plume centerline, hence exiting the river plume sooner than the probes in the two other realizations.

Probe 8 experienced a lack of data in Realizations 1 and 3 (after $200 \mathrm{~m}$ ), most likely due to a lost GPS lock that stopped the recording. The same probe in the second realization experienced rather low values (compared to the other probes), as its trajectory was mainly in the plume centerline, therefore recording mostly river dominated temperatures $\left(16-18^{\circ} \mathrm{C}\right)$, which are lower than the temperature of the ambient coastal sea $\left(21-22^{\circ} \mathrm{C}\right)$. Probe 2 , for instance, lost information for the last realization at less than $200 \mathrm{~m}$, which was caused by battery depletion. These data losses for Probes 2 and 8 are visible in all sensor's data in the third realization (see the corresponding panels in Figures 15-17).

Measured temperature profiles for all realizations
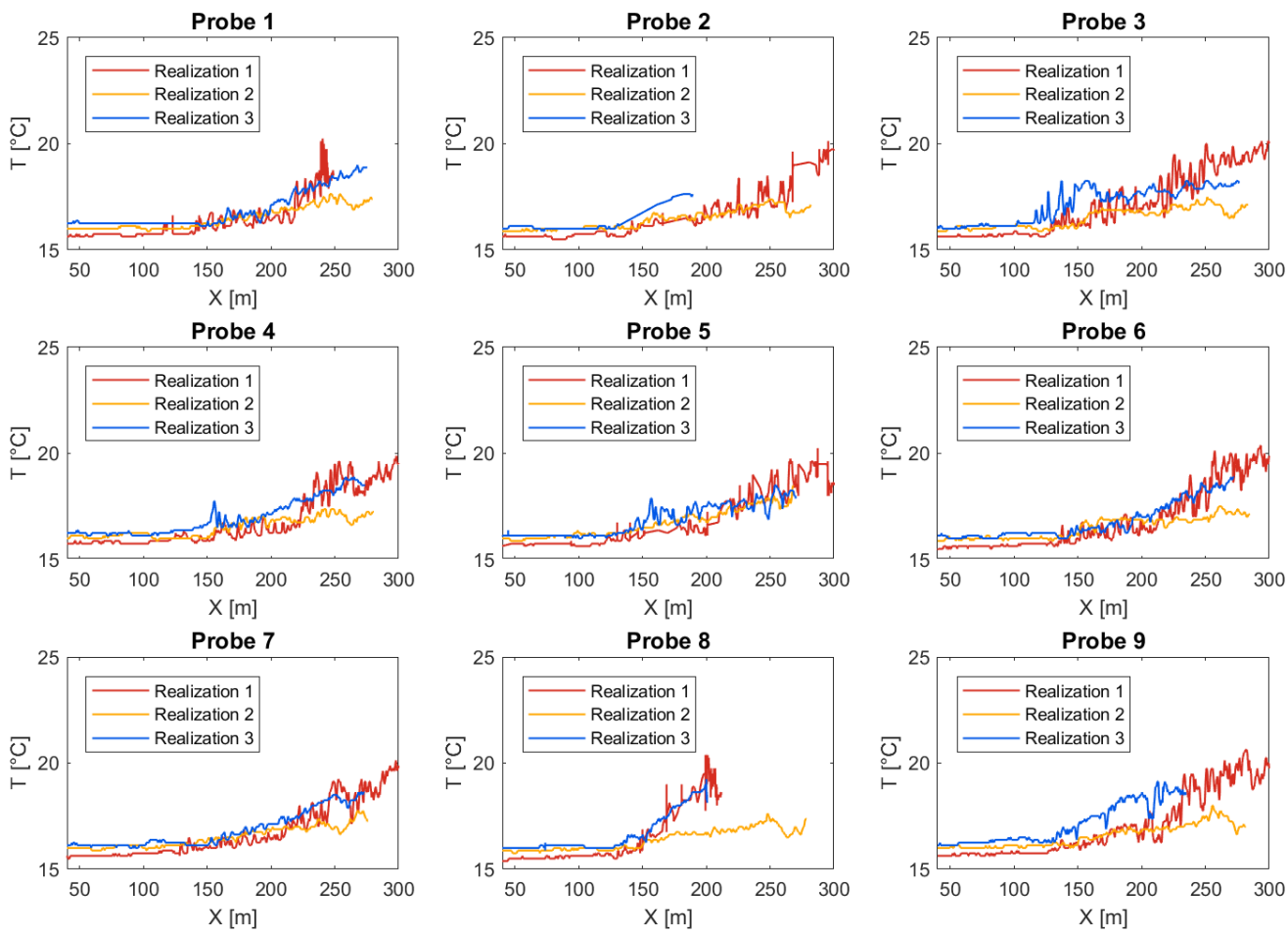

Figure 16. Measured temperature. 
Calibrated EC profiles from ADC output for all realizations
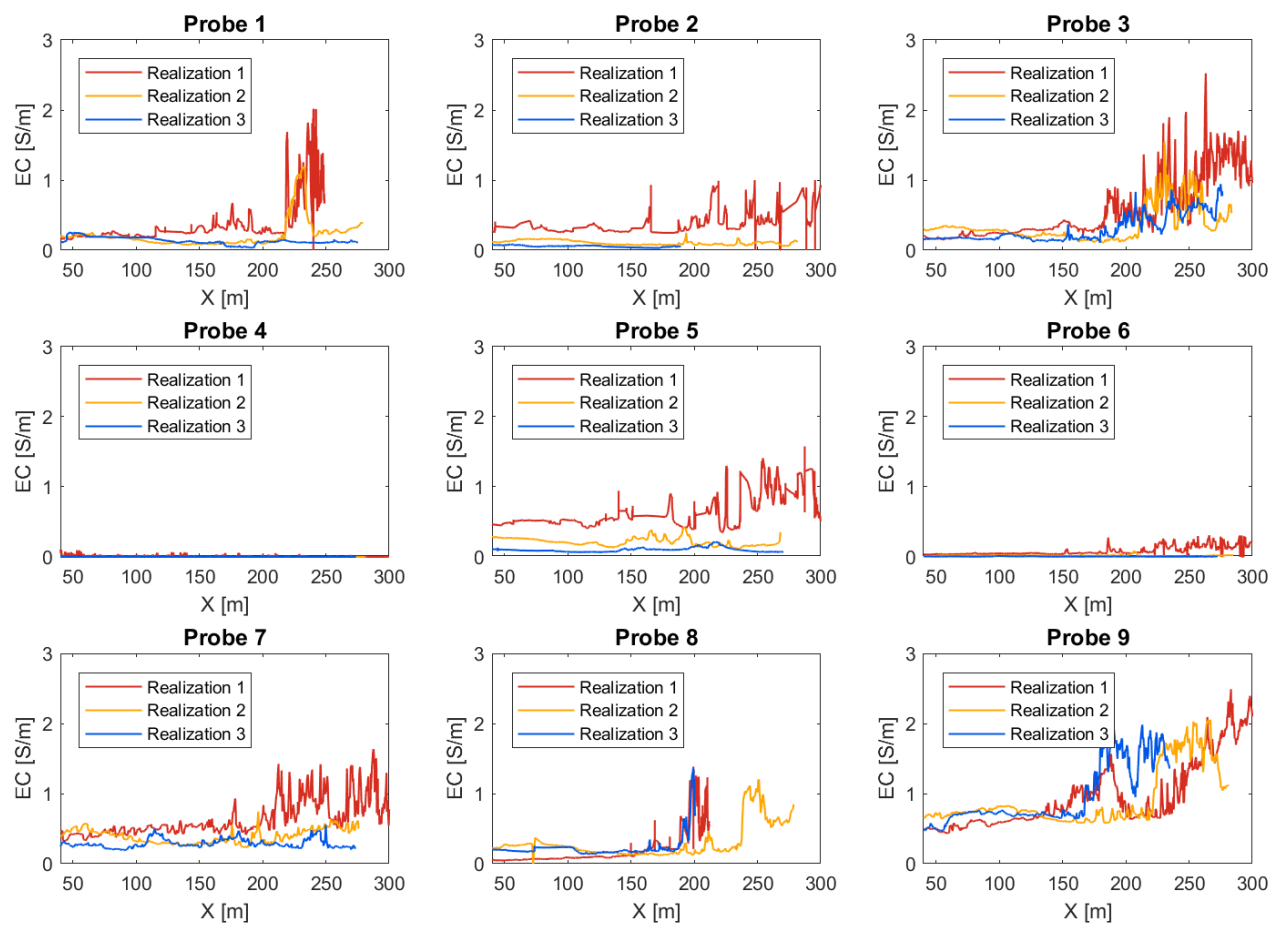

Figure 17. Measured electrical conductivity (EC). Analog digital converter (ADC).

The electrical conductivity sensor, as expected, was shown to be the most sensitive one. As described in Sections 2.3 and 2.4, it is a plate with one pair of active electrodes in the form of keel below the plastic container, which acts as a mini-floater. The keel enabled the mini-floater to be more stabilized in the water; however, when surface rips were caused by occasional light wind blows, sporadic vegetation, and local waves emanating from passing boats, some of the air got stuck between the keel and the plastic container, rendering the EC measurement useless. Two probes, namely Probes 4 and 6, experienced total failure in recording the EC. Later, we discovered that water had entered the part of the EC module circuit (positioned on the keel) that was insufficiently water-proofed.

Nevertheless, the expected behavior of electrical conductivity (EC) was still observed in the rest of the probes.

Finally, salinity data for each probe were obtained by implementing the calculation described in Section 2.4.3, as presented in Figure 18.

As already established, there are no significant differences between conductivity and salinity behavior trends, as salinity was obtained from Equation (3), with domination of the conductivity's influence. 


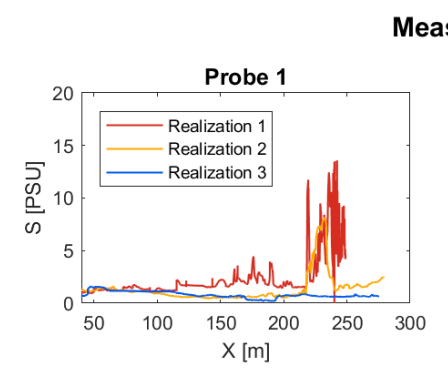

Measured salinity profiles for all realizations
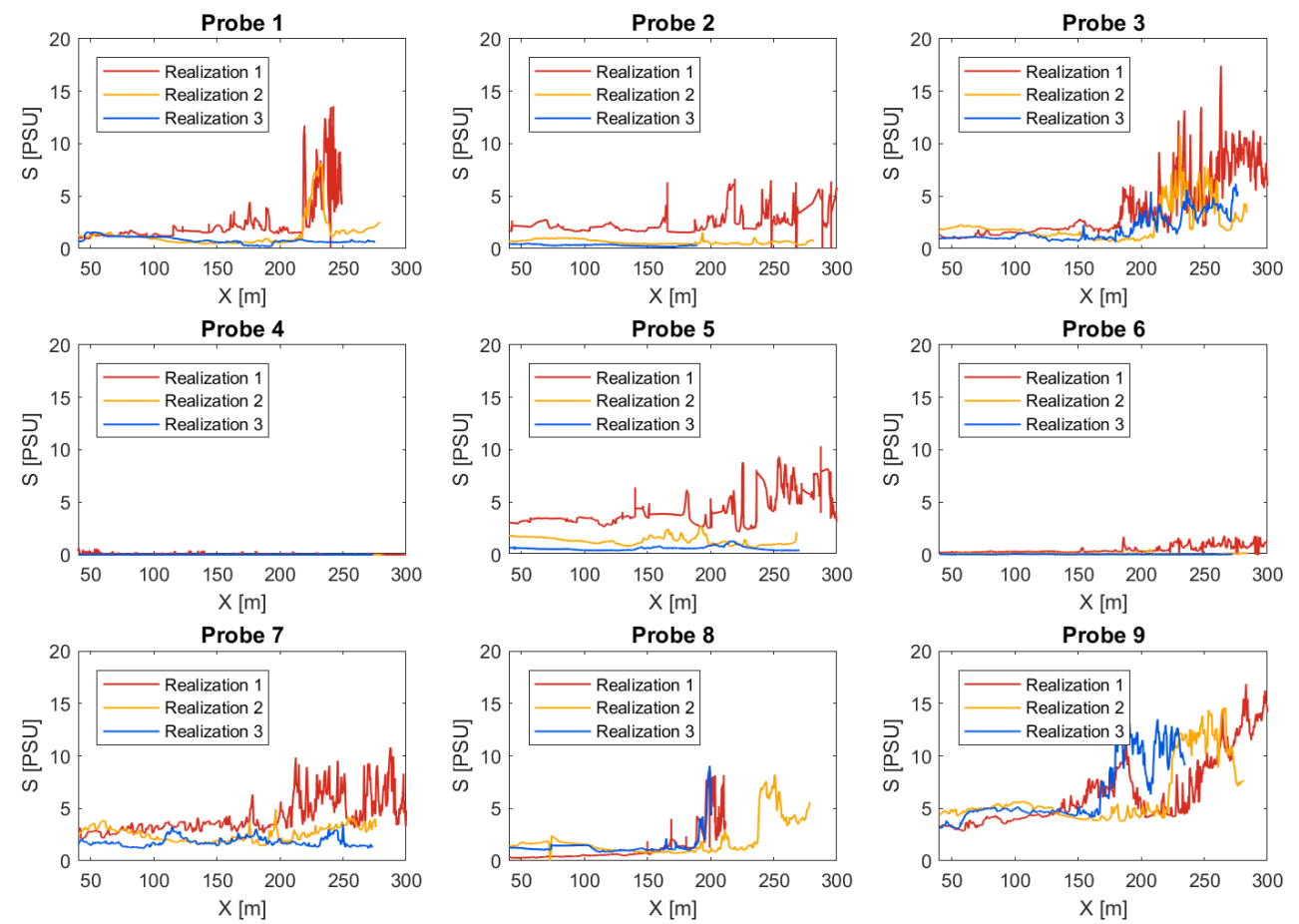

Figure 18. Measured salinity in practical salinity units (PSU).

\subsection{Application Potential}

An important application of the research was tested by comparing the velocity data with previously defined analytical expressions (Equation (4)). In addition, both salinity and temperature were tested as potential concentration proxies for conservative solutes.

\subsubsection{Velocity Model}

In our previous research, several measurements were conducted at the River Žrnovnica, as explained in [24,41], and, from those results, an approximation for the depth-integrated mean velocity $U$ in the near-field area of an estuary and a steady source was given:

$$
U(x)=U_{0} e^{-v x}
$$

where $U_{0}$ is the cross-sectionally averaged velocity at the river mouth and $v\left[\mathrm{~m}^{-1}\right]$ is an attenuation coefficient representing all potential mechanisms (bathymetry, tides, wind, etc.) that, when combined, concur to progressively reduce $U$ in the $x$ direction [42].

The proposed exponential attenuation model for mean velocity was already tested and compared to the existing theoretical model for jet flow [67] and hydrodynamic model MOHID [68]. However, the intent was to obtain an easier way to measure downstream velocities simultaneously and obtain the attenuation coefficient $v\left[\mathrm{~m}^{-1}\right]$. Hence, in each realization (different panels in Figure 19), a regression analysis was applied (using the root mean square error) to find the optimal parameters, $U_{0}$ and $v$, for each probe. The final values in figures are averaged for all corresponding probes in a realization. As mentioned above, not all probes succeeded in obtaining the relevant velocity data in each realization (due to technical difficulties), which is why their velocity profiles were not taken into account. Nevertheless, parameters were obtained, including the initial velocity, in a range from 0.3 to $0.37 \mathrm{~m} / \mathrm{s}$, which is close to $0.29 \mathrm{~m} / \mathrm{s}$, measured by hydrometric wing (Section 2.2), and having an attenuation coefficient in a rather low range from 0.0003 to $0.0022 \mathrm{~m}^{-1}$. The velocity obtained by 
the presented probe system is strictly a surface one. However, since the studied estuary is stratified, most of the flow is contained in the upper river's buoyant plume that becomes thinner along the downstream direction. This is also a reason for a slightly higher initial velocity obtained by the fitting procedure described above. The attenuation coefficient is low due to the steady conditions in the estuary with little or no wind at all, and small tide conditions in the already very closed Kaštela Bay, and therefore quite limited impact of the velocity attenuation. Moreover, in this case, one may consider the mean velocity to be constant in the near-field zone of the corresponding estuary.
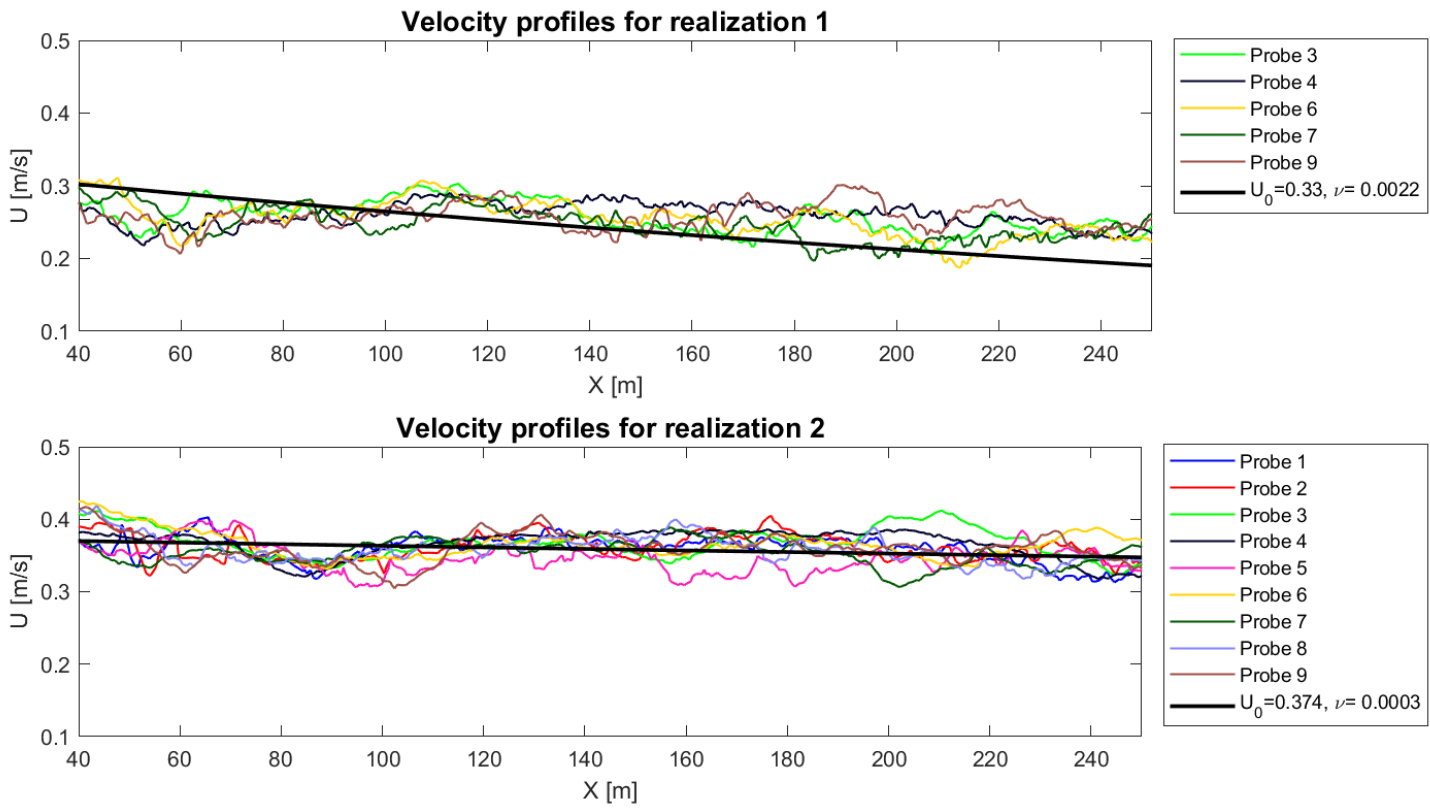

Velocity profiles for realization 3
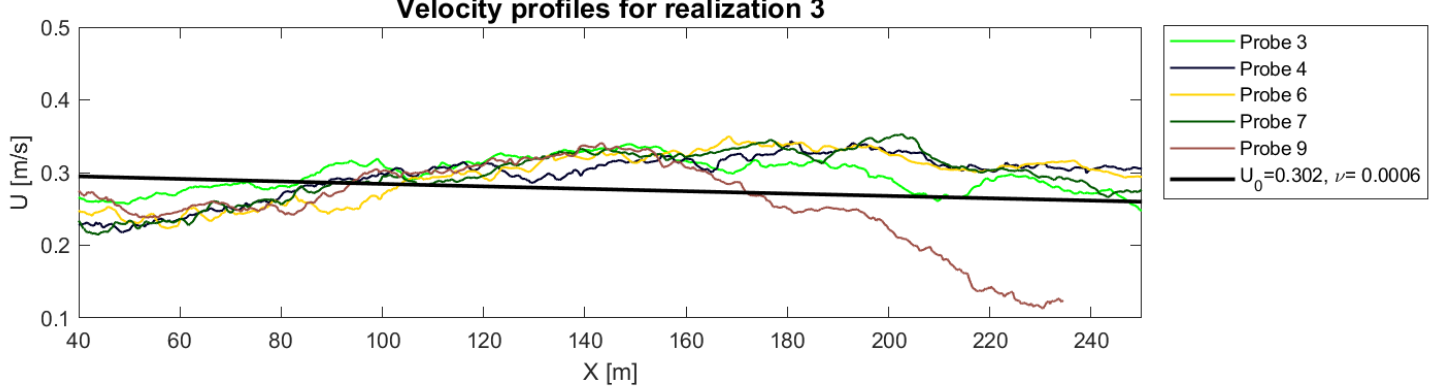

Figure 19. Velocity model parameters.

\subsubsection{Concentration Proxy}

Both temperature and salinity epitomize crucial parameters in an estuary, from their physical variability to the impact they cause on hydrodynamic conditions as well as the estuarine biome. Due to such importance, and thanks to the current and rising measurement abilities, those two properties are among the most monitored and used data, which makes them an attractive alternative for emulation of an actual, mostly conservative, solute transport. Several studies used salinity $[33,35,36,38,39]$ or temperature $[33,69,70]$ as an indicator for other properties in rivers and estuaries. Hence, sea water dilution (supported by both salinity and temperature data) may be considered as an inverse process to river transport by freshwater discharge, as freshwater both dilutes the salinity and decreases the temperature. Salinity was proposed in [40-42] as a proxy for normalized concentration in the surface water layer:

$$
C_{p}^{S}(\mathbf{x}, t)=1-\frac{S(\mathbf{x}, t)-S_{\min }}{S_{\max }-S_{\min }}
$$


where $S(\mathbf{x}, t)$ is the measured surface salinity value at point $\mathbf{x}$ and time $t, S_{\min }$ is the initial salinity measured at the river mouth (considered to be the minimal one at the area of interest), and $S_{\max }$ represents the ambient sea surface salinity in the estuary. Such utilization of salinity data may be possible only when the steady-state assumption is valid, such as when other factors (e.g., wind currents and tides) have a minimal effect on the estuary [35]. To ensure steadiness in both flow and water levels of the river, an adequate time period from the most recent precipitation was required. Therefore, weather forecast and tide predictions were taken into account when choosing dates for the measurement campaigns.

Furthermore, temperature seemed to have a similar behavior, thus the same procedure defined by Equation (5) was applied to temperature data, including the choice of minimal surface temperature $T_{\min }$ as the initial one (at the river mouth) and $T_{\max }$ as the ambient sea surface temperature in the estuary:

$$
C_{p}^{T}(\mathbf{x}, t)=1-\frac{T(\mathbf{x}, t)-T_{\min }}{T_{\max }-T_{\min }}
$$

When wakes, jets, and plumes are considered, a Gaussian one-dimensional distribution may be assumed for cross-sectional profiles [71-73]. In our previous research, we applied such definition of solute mean concentration on a plane normal to the mean flow direction for the near-field zone of an estuary exhibiting steady flow with a steady source [24,40,42,74]:

$$
\bar{c}(y, x)=\frac{L}{\sigma_{y} \sqrt{2 \pi}} e^{\frac{-y^{2}}{2 \sigma_{y}^{2}}}
$$

where $L=\frac{\dot{m}}{B U_{0}}$ is a steady mass loading of the solute through the plane normal to the flow direction $x$, defined by steady mass flux $(\dot{m})$, river mouth width $(B)$, and the initial velocity $\left(U_{0}\right)$. The spatial variance is defined by $\sigma_{y}^{2}=2 e_{t} t+\sigma_{y_{0}}^{2}, x=U t$, where $e_{t}\left(\mathrm{~m}^{2} / \mathrm{s}\right)$ is the constant spatial variance growth rate (equivalent to turbulent diffusivity) across the flow in the direction $y$, and $\sigma_{y_{0}}^{2}$ represents the initial variance at $x=0$.

On that note, we wanted to test how well the measured data match the assumed Gaussian analytical model, and if so, what parameters might be obtained for further analytical modeling. Measured temperature and salinity, as described in Section 2, were sampled with an $8 \mathrm{~Hz}$ frequency, and with a velocity of probes ranging from 0.4 to $0.2 \mathrm{~m} / \mathrm{s}$ (Figure 15). We obtained 20-40 points per $1 \mathrm{~m}$ of probe trajectory. By taking trajectories for all three releases of probes (realizations), both salinity and temperature proxy data were obtained (using Equations (5) and (6)) and surface fitted by Gaussian distribution (Equation (7)). In Figure 20, we present the aforementioned surface fit for both temperature proxy concentration (Figure 20, top) and for salinity proxy concentration (Figure 20, bottom) with corresponding parameters and the statistics for goodness of fit $\left(R^{2}\right.$ and RMSE). The parameters that were optimized to obtain the fit are spatial variance growth rate $\left(e_{t}\right)$, effective source width or initial spatial variance $\left(\sigma_{y_{0}}\right)$, and the angle $(\alpha)$. $\alpha$ represents the rotation of the local coordinate system with regards to the UTM coordinates as presented:

$$
\begin{aligned}
& x=\left(x_{U T M}-x_{U T M, 0}\right) \cos \alpha-\left(y_{U T M}-y_{U T M, 0}\right) \sin \alpha \\
& y=\left(x_{U T M}-x_{U T M, 0}\right) \sin \alpha+\left(y_{U T M}-y_{U T M, 0}\right) \cos \alpha
\end{aligned}
$$

where $x_{U T M, 0}$ and $y_{U T M, 0}$ are corresponding UTM coordinates of the source. The obtained fit slightly better presents the proxy defined by salinity with the coefficient of determination, $R^{2}=0.803$ versus $R^{2}=0.749$ for temperature proxy. Similarly, the residuals for temperature proxy are more spread out from the Gaussian fit with $R M S E=0.123$, which is an almost two times larger scattering than with the salinity proxy $(R M S E=0.0777)$. In addition, it should be noted that, although temperature and salinity are measured through different devices, the fitted parameters, i.e., $e_{t}=0.143 \mathrm{~m}^{2} / \mathrm{s}$ and $\alpha=200$ for temperature and $e_{t}=0.0856 \mathrm{~m}^{2} / \mathrm{s}$ and $\alpha=198$ for salinity, are on the same order of magnitude. 
This evidence gives more reliability to our data, which are able to picture the main physical behavior of the contaminant dispersion in the estuary environment.
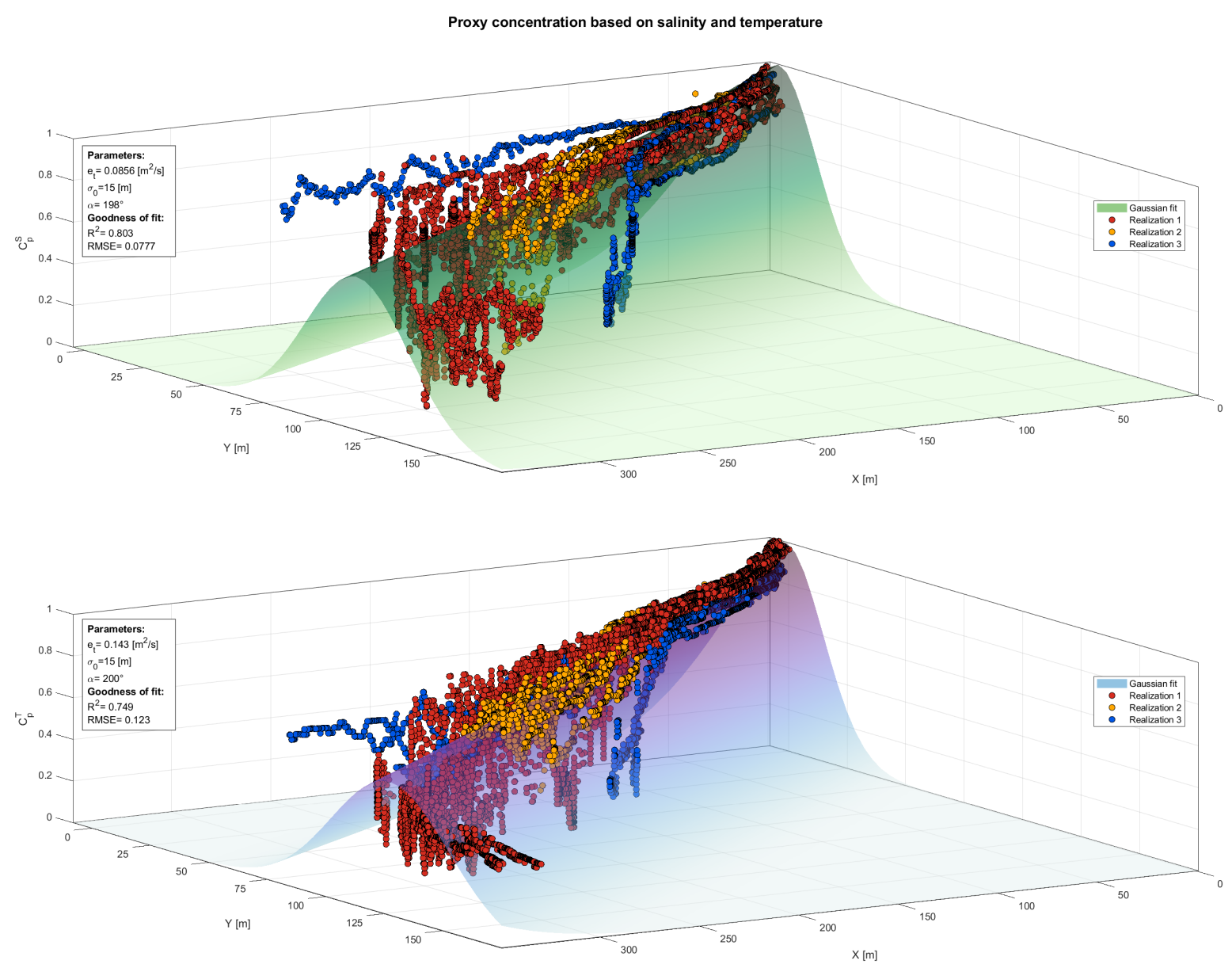

Figure 20. Comparison between the measured data and Gaussian mean distribution for: salinity as a concentration proxy (top); and temperature as a concentration proxy (bottom).

Conclusively, this procedure has confirmed our previous work on using salinity as a proxy for conservative solute transport when compared with analytical solutions for mean concentration in a steady state with a steady source. However, an unexpected bonus from this procedure was the option for obtaining the spatial variance growth rate, which is equivalent to turbulent diffusivity and one of the physical parameters that is very difficult to measure, directly or otherwise [21,75].

\subsection{Discussion and Lessons Learned}

To test the behavior and variability of measured temperature and salinity data within the proposed measurement system, a corresponding coefficient of variation (CV) was calculated. The coefficient of variation is defined as the ratio between the standard deviation to the mean and, therefore, it is used to quantify the degree of dispersion of a sample. The CV of temperature and salinity for all trajectories in each realization is presented in Figure 21. 


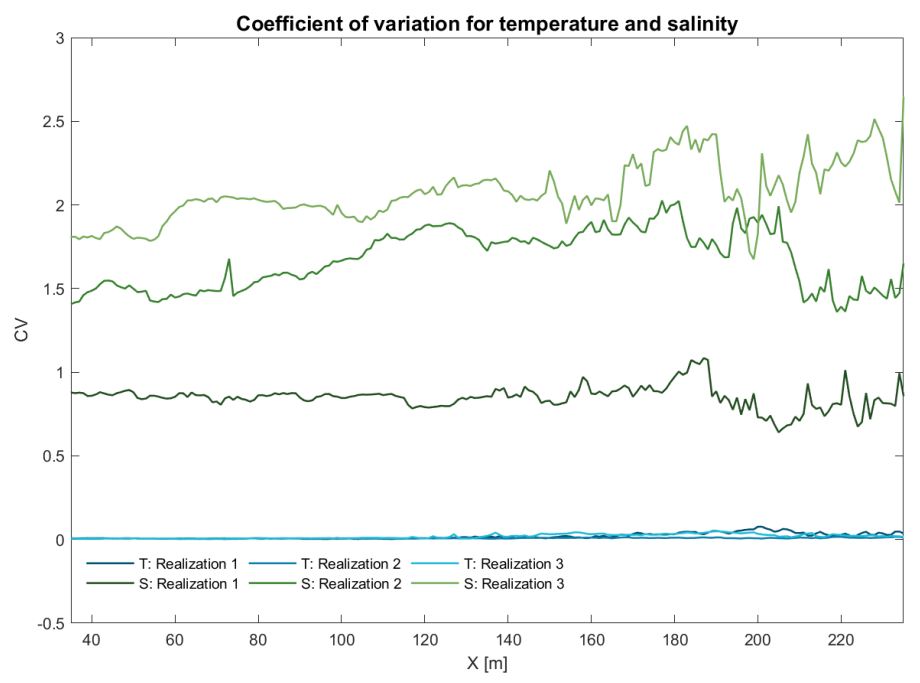

Figure 21. Coefficient of variation (CV) for temperature and salinity in the down stream direction.

The results show an expected low level (less than 10\%) of temperature variability between the probes and realizations, confirming that the temperature has stable behavior. Conversely, salinity exhibits rather high variability. Even though this high variability is partially a function of a conductivity sensor being more susceptible to environmental conditions, it also confirms the higher dispersion that both conductivity and salinity exhibit in the estuary where mixing is an important feature $[71,76,77]$.

As already established, the conditions in the investigated estuary belong to a predominantly stationary process, and therefore we used the fast Fourier transform of normalized temperature, conductivity, and salinity data to obtain the power spectral density (PSD) estimate [78,79]. Hence, in Figure 22, single-sided PSDs are shown.

The key finding related to the spectral domain (Figure 22) implies that the salinity measured by developed probes is not simply an unorganized random field (in the case the PSD was showing a constant line over all available frequencies), but rather distributed over lower frequencies (e.g., $0-0.15 \mathrm{~Hz}$ ); therefore, the variability was a function of long period changes, which is consistent with the examined physical problem. The presented signal also resembles a pink noise with an almost systematic reduction of PSD along the frequencies. As expected, since EC is a more influential variable than temperature in Equation (3), salinity variance is more aligned to the EC variance (see Figure 22).

To apply this measurement system, a steady state should be established. When steady state conditions are met, one may consider the salinity behavior equivalent to a conservative tracer transport coming from the river. This steady-state assumption has been proven by steady velocity profiles (Figure 19) and the PSDs above (Figure 22). On the other hand, if probes are going to be used as Lagrangian style surface drifters (similar to [46]), they represent cheap and efficient tracers in any environmental conditions; however, the GPS precision should be improved by implementation of RTK (real-time kinematic) system GPS, or by adding additional inertial measurement systems. Furthermore, to have adequate conductivity/salinity measurements in that system, some weight to probe containers should be added along with better keel shaping to avoid air bubbles below them (which caused our conductivity data stream to be interrupted). The parts of the EC circuit that are positioned on a keel should be meticulously tested for being water proof, in order to avoid the problems that we encountered in the field (Probes 4 and 6). 


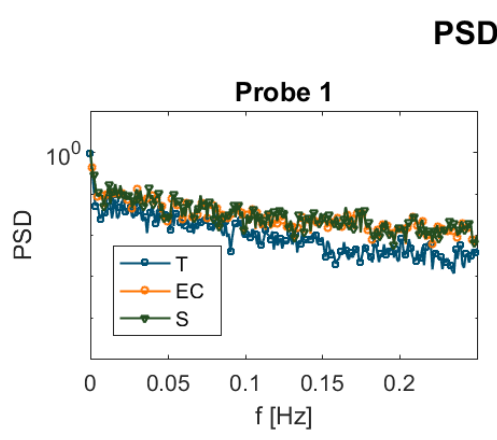

PSD of normalized fluctuations for realization 1
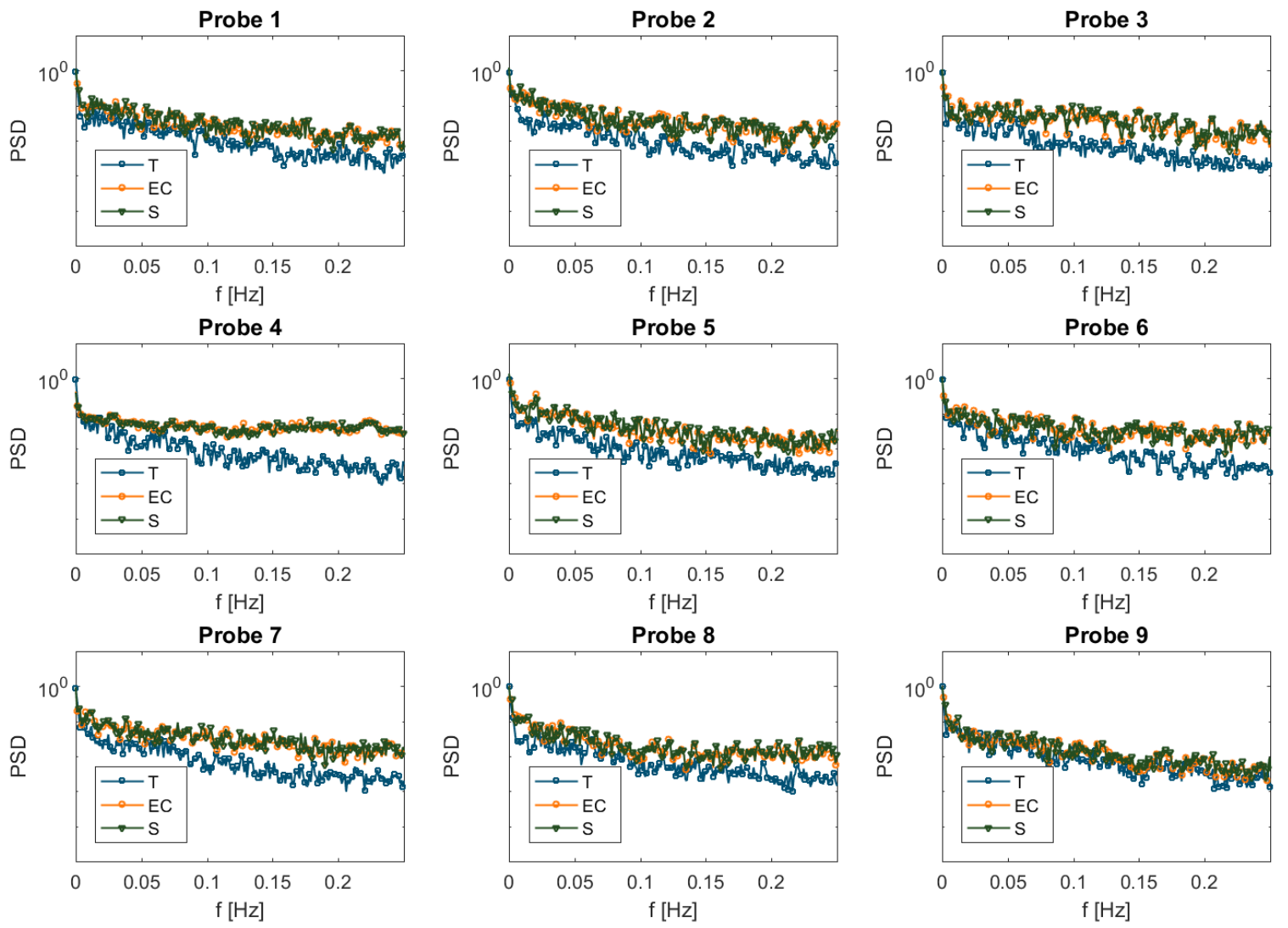

Figure 22. Power spectral density (PSD) of normalized fluctuations for temperature (T), electrical conductivity (EC), and salinity (S) in Realization 1.

However, using the salinity data as a concentration proxy for conservative solute becomes challenging, since the mixing in higher waves, or increased sea current effects, would become more pronounced, hence diminishing the river domination as a key assumption for using the analytical models by Galešić et al. [24], Andričević and Galešić [40]. Nevertheless, if successful, all acquired data may be very useful for describing hydrodynamics in the estuary in different conditions, which may be later compared to numerical models, and even help in calibrating them.

\section{Conclusions and Future Remarks}

In this paper, we present an innovative low-cost measurement system for surface water properties. At the time of the development, the resources needed for building one probe included approximately 130 EUR of materials and up to $22 \mathrm{~h}$ of engineering work. These costs are two orders of magnitude lower than corresponding off-the-shelf solutions, which additionally require significant modifications to fit specific application needs.

Furthermore, an important goal of this study was to test if the proposed system of probes is satisfactory to obtain quality data on temperature, salinity, and velocities in the near field zone of an estuary. The obtained results deliver promising functionality for surface salinity data, downstream surface velocities, and surface temperature. However, for more detailed and depth-related information on salinity, researchers would need different equipment. Thanks to the multiple probe-releasing option, the velocity field is rather easily obtained from GPS data. The measured velocity is in agreement with the attenuation model proposed by Galešić et al. [24]. Moreover, one may obtain the velocity attenuation coefficient in this way with only one realization by averaging the velocity profiles of all probes. As expected, several problems were detected, starting from the electrical conductivity sensor, 
which should be made more range oriented, i.e., if salinity is expected to appear out of the range 2-25 PSU, the corresponding electrodes (as presented in Figure 6) should have multiple sensitivity real-time switchable settings.

Furthermore, this kind of free probe-release is best applied to steady and calm surface conditions. Otherwise, sudden waves resulting from passing boats, birds, or wind may interfere with the data acquisition. However, such stabilization problems might be solved with different keel shaping and by adding some additional weight to the probe. Lithium-ion batteries have shown to be an effective solution for these short term measurements (up to $8 \mathrm{~h}$, which is more than the relatively steady conditions may appear anyway), although they should be frequently checked. In addition, an idea was brought to attention while processing GPS data to obtain velocity: one may include the inertial measurement units (IMU), such as accelerometers, gyrometers, and magnetometers, to have more quality and controlled information.

The presented prototype may be one of the first steps toward development of a more complex monitoring system applicable in a broader range of conditions, which has potential for further research. However, it is important to emphasize that this drifter system was specifically developed to simultaneously obtain data on surface salinity concentrations in multiple points, in order to improve the validation of analytical models for conservative solute transport (both Galešić et al. [24] and Andričević and Galešić [40]). Currently ongoing research includes the analysis of data when probes were fixed on chosen stream-wise or cross-stream profiles, therefore obtaining rich datasets at multiple points (measurements conducted on 12 and 13 July 2018). Data at fixed points enable testing the statistics with analytical models for both point defined statistics (probability density functions and their moments) and spatially integrated statistics (expected mass fraction and spatially integrated moments). Since typical tracer releases (e.g., [22]) are difficult, expensive, and time consuming to obtain adequate statistics, salinity emerged as a convenient proxy.

The aforementioned models analyzed the worst-case scenario where the lack of wind stress and high tides reduce dilution of conservative pollution generated by the river. Therefore, the measurement conditions were chosen during low tide and low winds on purpose.

Among the future research directions is also the integration of measured data within MSDI according to the INSPIRE Directive and associated regulations. Data from different sensors, as well as data from other sources, might be integrated to create a comprehensive data web stream for analysis, which should yield more precise and accurate data models.

Author Contributions: Conceptualization, V.D., M.G., M.D.D., M.T., and R.A.; Funding acquisition, M.G. and R.A.; Investigation, V.D., M.G., M.D.D., and M.T.; Methodology, V.D., M.G., M.D.D., and R.A.; Visualization, M.G., M.D., and M.T.; Writing—original draft, V.D. and M.G.; and Writing—review and editing, M.D.D., M.T., and R.A. All authors have read and agreed to the published version of the manuscript.

Funding: This research was partially supported through project KK.01.1.1.02.0027, a project co-financed by the Croatian Government and the European Union through the European Regional Development Fund-the Competitiveness and Cohesion Operational Programme, Contract Number: KK.01.1.1.02.0027. Additionally, the research was supported by next two projects: STIM-REI (Center of Excellence for Science and Technology-Integration of Mediterranean Region (STIM), connecting research (R), education (E) and innovation (I)), a project funded by European Union from European Structural and Investment Funds 2014.-2020., Contract Number: KK.01.1.1.01.0003, and CAAT (Coastal Auto-purification Assessment Technology) also funded by European Union from European Structural and Investment Funds 2014.-2020., Contract Number: KK.01.1.1.04.0064.

Acknowledgments: We thank Koča Vrančić for important help during the development of the prototype for measurement system. Furthermore, we thank Ana Ricov for valuable help during the measurement campaigns.

Conflicts of Interest: The authors declare no conflict of interest. 


\section{References}

1. Elliott, M.; Whitfield, A.K. Challenging paradigms in estuarine ecology and management. Estuar. Coast. Shelf Sci. 2011, 94, 306-314. [CrossRef]

2. Halpern, B.S.; Walbridge, S.; Selkoe, K.A.; Kappel, C.V.; Micheli, F.; D’agrosa, C.; Bruno, J.F.; Casey, K.S.; Ebert, C.; Fox, H.E.; et al. A global map of human impact on marine ecosystems. Science 2008, 319, 948-952. [CrossRef] [PubMed]

3. Wolanski, E.; Elliott, M. Estuarine Ecohydrology: An Introduction; Elsevier: Amsterdam, The Netherlands, 2015.

4. Assessment, M.E. Ecosystems and Human Well-Being; Island Press: Washington, DC, USA, 2005; Volume 5.

5. Barbier, E.B.; Hacker, S.D.; Kennedy, C.; Koch, E.W.; Stier, A.C.; Silliman, B.R. The value of estuarine and coastal ecosystem services. Ecol. Monogr. 2011, 81, 169-193. [CrossRef]

6. Barbier, E.B. Progress and Challenges in Valuing Coastal and Marine Ecosystem Services. Rev. Environ. Econ. Policy 2011, 6, 1-19. [CrossRef]

7. Milon, J.W.; Alvarez, S. The Elusive Quest for Valuation of Coastal and Marine Ecosystem Services. Water 2019, 11, 1518. [CrossRef]

8. Copeland, C. Clean Water Act: A Summary of the Law; Congressional Research Service, Library of Congress: Washington, DC, USA, 1999.

9. European Community. Directive 2000/60/EC of the European Parliament and of the Council of 23 October 2000 Establishing a Framework for Community Action in the Field of Water Policy; Official Journal of the European Communities (L 327/1-73); European Community: Brussels, Belgium, 2000.

10. European Community. Bathing Water Quality Directive 2006/7/EC; Official Journal of the European Union (OJ L 64); European Community: Brussels, Belgium, 2006.

11. European Community. Directive 2008/56/EC of the European Parliament and of the Council of 17 June 2008 Establishing a Framework for Community Action in the Field of Marine Environmental Policy (Marine Strategy Framework Directive); Official Journal of the European Union (L 164/19-40); European Community: Brussels, Belgium, 2008.

12. Guerry, A.D.; Plummer, M.L.; Ruckelshaus, M.H.; Harvey, C.J. Ecosystem service assessments for marine conservation. In Natural Capital: Theory and Practice of Mapping Ecosystem Services; Oxford University Press: Oxford, UK, 2011; pp. 296-322.

13. Pinto, R.; de Jonge, V.N.; Neto, J.M.; Domingos, T.; Marques, J.C.; Patrício, J. Towards a DPSIR driven integration of ecological value, water uses and ecosystem services for estuarine systems. Ocean. Coast. Manag. 2013, 72, 64-79. [CrossRef]

14. Tosic, M.; Restrepo, J.D.; Izquierdo, A.; Lonin, S.; Martins, F.; Escobar, R. An integrated approach for the assessment of land-based pollution loads in the coastal zone. Estuar. Coast. Shelf Sci. 2018, 211, 217-226. [CrossRef]

15. Townsend, M.; Davies, K.; Hanley, N.; Hewitt, J.E.; Lundquist, C.J.; Lohrer, A.M. The Challenge of Implementing the Marine Ecosystem Service Concept. Front. Mar. Sci. 2018, 5, 1-13. [CrossRef]

16. European, C. Directive 2007/2/EC of the European Parliament and of the Council of 14 March 2007 Establishing an Infrastructure for Spatial Information in the European Community (INSPIRE); Official Journal of the European Communities (L 108/1-14); European Community: Brussels, Belgium, 2007.

17. Longhorn, R.A. Coastal spatial data infrastructure. In GIS for Coastal Zone Management; CRC Press: Boca Raton, FL, USA, 2004; pp. 1-14.

18. Tavra, M.; Jajac, N.; Cetl, V. Marine Spatial Data Infrastructure Development Framework: Croatia Case Study. ISPRS Int. J. Geo-Inf. 2017, 6, 117. [CrossRef]

19. European, C. INSPIRE Geoportal. 2019. Available online: https://inspire-geoportal.ec.europa.eu (accessed on 5 October 2019).

20. Borja, A.; Bricker, S.B.; Dauer, D.M.; Demetriades, N.T.; Ferreira, J.G.; Forbes, A.T.; Hutchings, P.; Jia, X.; Kenchington, R.; Marques, J.C.; et al. Overview of integrative tools and methods in assessing ecological integrity in estuarine and coastal systems worldwide. Mar. Pollut. Bull. 2008, 56, 1519-1537. [CrossRef]

21. Riddle, A.; Lewis, R. Dispersion experiments in UK coastal waters. Estuar. Coast. Shelf Sci. 2000, 51, $243-254$. [CrossRef] 
22. Rodriguez, A.; Sánchez-Arcilla, A.; Redondo, J.M.; Bahia, E.; Sierra, J.P. Pollutant dispersion in the nearshore region: Modelling and measurements. Water Sci. Technol. 1995, 32, 169-178. [CrossRef]

23. Clarke, L.; Ackerman, D.; Largier, J. Dye dispersion in the surf zone: Measurements and simple models. Cont. Shelf Res. 2007, 27, 650-669. [CrossRef]

24. Galešić, M.; Andričević, R.; Gotovac, H.; Srzić, V. Concentration statistics of solute transport for the near field zone of an estuary. Adv. Water Resour. 2016, 94, 424-440. [CrossRef]

25. Galešić, M.; Andričević, R.; Divić, V.; Šakić Trogrlić, R. New screening tool for obtaining concentration statistics of pollution generated by rivers in estuaries. Water 2018, 10, 639. [CrossRef]

26. Plew, D.R.; Zeldis, J.R.; Shankar, U.; Elliott, A.H. Using Simple Dilution Models to Predict New Zealand Estuarine Water Quality. Estuaries Coasts 2018, 41, 1643-1659. [CrossRef]

27. Estevez, E.D. Review and assessment of biotic variables and analytical methods used in estuarine inflow studies. Estuaries 2002, 25, 1291-1303. [CrossRef]

28. Savenije, H.H. Salinity and Tides in Alluvial Estuaries; Elsevier: Amsterdam, The Netherlands, 2005; p. 194.

29. Wiseman, W.J.; Swenson, E.M.; Power, J. Salinity trends in Louisiana estuaries. Estuaries 1990, 13, $265-271$. [CrossRef]

30. Bradley, P.M.; Kjerfve, B.; Morris, J.T.; Kjerfve, B. Rediversion Salinity Change in the Cooper River, South Carolina: Ecological Implications. Estuaries 1990, 13, 373. [CrossRef]

31. Lorenz, J.J. A review of the effects of altered hydrology and salinity on vertebrate fauna and their habitats in northeastern Florida Bay. Wetlands 2014, 34, 189-200. [CrossRef]

32. Spalding, E.A.; Hester, M.W. Interactive effects of hydrology and salinity on oligohaline plant species productivity: Implications of relative sea-level rise. Estuaries Coasts 2007, 30, 214-225. [CrossRef]

33. Rivera-Monroy, V.H.; Twilley, R.R.; Mancera-Pineda, J.E.; Madden, C.J.; Alcantara-Eguren, A.; Moser, E.B.; Jonsson, B.F.; Castañeda-Moya, E.; Casas-Monroy, O.; Reyes-Forero, P.; et al. Salinity and Chlorophyll a as Performance Measures to Rehabilitate a Mangrove-Dominated Deltaic Coastal Region: The Ciénaga Grande de Santa Marta-Pajarales Lagoon Complex, Colombia. Estuaries Coasts 2011, 34, 1-19. [CrossRef]

34. Little, S.; Wood, P.J.; Elliott, M. Quantifying salinity-induced changes on estuarine benthic fauna: The potential implications of climate change. Estuar. Coast. Shelf Sci. 2017, 198, 610-625. [CrossRef]

35. Vallino, J.; Hopkinson, J.C.S. Estimation of Dispersion and Characteristic Mixing Times in Plum Island Sound Estuary. Estuar. Coast. Shelf Sci. 1998, 46, 333-350. [CrossRef]

36. Ho, D.T.; Schlosser, P.; Caplow, T. Determination of Longitudinal Dispersion Coefficient and Net Advection in the Tidal Hudson River with a Large-Scale, High Resolution SF6 Tracer Release Experiment. Environ. Sci. Technol. 2002, 36, 3234-3241. [CrossRef]

37. Gay, P.; O'Donnell, J. Comparison of the salinity structure of the Chesapeake Bay, the Delaware Bay and Long Island Sound using a linearly tapered advection-dispersion model. Estuaries Coasts 2009, 32, 68-87. [CrossRef]

38. Xu, J.; Long, W.; Wiggert, J.D.; Lanerolle, L.W.J.; Brown, C.W.; Murtugudde, R.; Hood, R.R. Climate Forcing and Salinity Variability in Chesapeake Bay, USA. Estuaries Coasts 2012, 35, 237-261. [CrossRef]

39. Troselj, J.; Sayama, T.; Varlamov, S.M.; Sasaki, T.; Racault, M.F.; Takara, K.; Miyazawa, Y.; Kuroki, R.; Yamagata, T.; Yamashiki, Y. Modeling of extreme freshwater outflow from the north-eastern Japanese river basins to western Pacific Ocean. J. Hydrol. 2017, 555, 956-970. [CrossRef]

40. Andričević, R.; Galešić, M. Contaminant dilution measure for the solute transport in an estuary. Adv. Water Resour. 2018, 117, 65-74. [CrossRef]

41. Galešić, M.; Andričević, R.; Divić, V.; Mateus, M.; Pinto, L. Potential data used for validation of concentration statistics obtained using analytical model for conservative transport in an estuary. EGU General Assembly 2016. Water Resour. 2016, 31, 714-725.

42. Galešić, M. Concentration Statistics for Conservative Solute Transport in River Estuaries. Ph.D. Thesis, University of Split, Split, Croatia, 2018.

43. Albaladejo, C.; Soto, F.; Torres, R.; Sánchez, P.; López, J.A. A low-cost sensor buoy system for monitoring shallow marine environments. Sensors 2012, 12, 9613-9634. [CrossRef]

44. Marcelli, M.; Piermattei, V.; Madonia, A.; Mainardi, U. Design and application of new low-cost instruments for marine environmental research. Sensors 2014, 14, 23348-23364. [CrossRef]

45. Arduino. What is Arduino. 2019. Available online: https://www.arduino.cc/en/Guide/Introduction (accessed on 5 October 2019). 
46. Lockridge, G.; Dzwonkowski, B.; Nelson, R.; Powers, S. Development of a low-cost arduino-based sonde for coastal applications. Sensors 2016, 16, 528. [CrossRef]

47. Legović, T. Exchange of water in a stratified estuary with an application to Krka (Adriatic Sea). Mar. Chem. 1991, 32, 121-135. [CrossRef]

48. Ljubenkov, I.; Vranješ, M. Zaslanjivanje ušća rijeke Jadro - mjerenje i hidrodinamičko modeliranje. Hrvat. Vode 2013, 545, 225-234.

49. Krvavica, N.; Travaš, V.; Ravlić, N.; Ožanić, N. Hydraulics of Stratified Two-layer Flow in Rječina Estuary. In Proceedings of the Landslides and Flood Hazard Assessment, Zagreb, Croatia, 6-9 March 2013; pp. 1-5.

50. Montagna, P.; Palmer, T.A.; Pollack, J.B. Hydrological Changes and Estuarine Dynamics; Springer Science \& Business Media: Berlin, Germany, 2012; Volume 8.

51. IZOR. Institute of Oceanography and Fisheries. 2019. Available online: http://www.izor.hr/ (accessed on 2 December 2019).

52. KeuwlsoftElectronics. 2019. Available online: http://www.keuwl.com/electronics.html (accessed on 5 October 2019).

53. ConductivityKit. 2019. Available online: https://www.atlas-scientific.com (accessed on 2 December 2019).

54. Microchip. 2019. Available online: https://www.microchip.com/wwwproducts/en/ATmega2560 (accessed on 5 October 2019).

55. National Marine Electronics Association. 2019. Available online: https://www.nmea.org (accessed on 5 October 2019).

56. MaximIntegrated. 2019. Available online: https://www.maximintegrated.com/en/products/sensors/ DS18B20.html (accessed on 5 October 2019).

57. U-blox. NEO-6 Series. 2019. Available online: https://www.u-blox.com/en/product/neo-6-series (accessed on 5 October 2019).

58. Jun, J.; Guensler, R.; Ogle, J.H. Smoothing methods to minimize impact of global positioning system random error on travel distance, speed, and acceleration profile estimates. Transp. Res. Rec. 2006, 1972, 141-150. [CrossRef]

59. De Boor, C. A Practical Guide to Splines; Springer: New York, NY, USA, 1978; Volume 27.

60. Antonov, J. World ocean atlas 2005, Volume 2: Salinity; NOAA Atlas NESDros. Information Service: Silver Spring, MD, USA, 2006; Volume 62.

61. Perkin, R.; Lewis, E. The Practical Salinity Scale 1978: Fitting the data. IEEE J. Ocean. Eng. 1980, 5, 9-16. [CrossRef]

62. Jones, G.R.; Nash, J.D.; Doneker, R.L.; Jirka, G.H. Buoyant surface discharges into water bodies. I: Flow classification and prediction methodology. J. Hydraul. Eng. 2007, 133, 1010-1020. [CrossRef]

63. MacCready, P.; Geyer, W.R. Advances in Estuarine Physics. Annu. Rev. Mar. Sci. 2009, 2, 35-58. [CrossRef] [PubMed]

64. Kuo, A.Y.; Neilson, B.J. Hypoxia and Salinity in Virginia Estuaries. Estuaries 1987, 10, 277. [CrossRef]

65. Trancart, T.; Feunteun, E.; Lefrançois, C.; Acou, A.; Boinet, C.; Carpentier, A. Difference in responses of two coastal species to fluctuating salinities and temperatures: Potential modification of specific distribution areas in the context of global change. Estuar. Coast. Shelf Sci. 2016, 173, 9-15. [CrossRef]

66. Pulina, S.; Satta, C.T.; Padedda, B.M.; Sechi, N.; Lugliè, A. Seasonal variations of phytoplankton size structure in relation to environmental variables in three Mediterranean shallow coastal lagoons. Estuar. Coast. Shelf Sci. 2018, 212, 95-104. [CrossRef]

67. Ozsoy, E.; Unluata, U. Ebb-tidal flow characteristics near inlets. Estuar. Coast. Shelf Sci. 1982, 14, $251-\mathrm{IN} 3$. [CrossRef]

68. MARETEC-IST. 2019. Available online: http://www.mohid.com (accessed on 5 October 2019).

69. O'Shea, M.L.; Brosnan, T.M. Trends in Indicators of Eutrophication in Western Long Island Sound and the Hudson-Raritan Estuary. Estuaries 2000, 23, 877. [CrossRef]

70. Araujo, A.V.; Dias, C.O.; Bonecker, S.L. Effects of environmental and water quality parameters on the functioning of copepod assemblages in tropical estuaries. Estuar. Coast. Shelf Sci. 2017, 194, 150-161. [CrossRef]

71. Fischer, H.B.; List, J.E.; Koh, C.R.; Imberger, J.; Brooks, N.H. Mixing in Inland and Coastal Waters; Academic Press: Cambridge, MA, USA, 1979; p. 302. 
72. Sawford, B.; Sullivan, P. A simple representation of a developing contaminant concentration field. J. Fluid Mech. 1995, 289, 141-157. [CrossRef]

73. Sullivan, P.J. The influence of molecular diffusion on the distributed moments of a scalar PDF. Environmetrics 2004, 15, 173-191. [CrossRef]

74. Di Dato, M.; Galešić, M.; Šimundić, P.; Andričević, R. A novel screening tool for the health risk in recreational waters near estuary: The Carrying Capacity indicator. Sci. Total. Environ. 2019, 694, 133584. [CrossRef]

75. Rutherford, J. River Mixing; John Wiley \& Sons Ltd.: Chichester, UK, 1994.

76. Ippen, A.; Eagleson, P. Estuary and Coastline Hydrodynamics; Engineering Societies Monographs; McGraw-Hill Book Co.: New York, NY, USA, 1966.

77. Savenije, H.H. Prediction in ungauged estuaries: An integrated theory. Water Resour. Res. 2015, 51, 2464-2476. [CrossRef]

78. Jacobsen, E.; Lyons, R. An update to the sliding DFT. IEEE Signal Process. Mag. 2004, 21, 110-111. [CrossRef]

79. Lyons, R.G. Understanding Digital Signal Processing, 3/E; Pearson Education India: London, UK, 2004.

(C) 2020 by the authors. Licensee MDPI, Basel, Switzerland. This article is an open access article distributed under the terms and conditions of the Creative Commons Attribution (CC BY) license (http:/ / creativecommons.org/licenses/by/4.0/). 